\title{
Testing for Unit Roots in Semi-Annual Data
}

\author{
Sandra G. Feltham ${ }^{a}$ and David E. A. Giles ${ }^{\text {b,* }}$ \\ ${ }^{a}$ Economic Analysis Branch, Ministry of Human Resources, Victoria BC, Canada \\ V8W1A4 \\ ${ }^{\mathrm{b}}$ Department of Economics, University of Victoria, Victoria BC, Canada V8W2Y2
}

August 1999

\begin{abstract}
We consider the problem of testing for unit roots at the zero and seasonal frequencies in timeseries data which are recorded semi-annually. The proposed methodology follows that of Hylleberg et al. (1990) and Beaulieu and Miron (1993) for quarterly and monthly data respectively. The non-standard asymptotic distributions for the single and joint tests are derived, and various percentiles of the finite-sample distributions are tabulated. Monte Carlo simulation is used to investigate the powers of the tests, and we illustrate their application to several semiannual economic time-series.
\end{abstract}

JEL classifications: $\quad \mathrm{C} 12, \mathrm{C} 22$

Keywords: $\quad$ Unit roots; non-stationary data; seasonality; semi-annual data

* Corresponding author. E-mail: dgiles@uvic.ca ; FAX: 250-721-6214 ; Voice: 250-721-8540 


\section{Introduction}

There is now a well-established literature relating to the problem of testing for non-stationarity in seasonal economic time-series data. For example, some of the earlier literature on this topic can be found in Hylleberg (1992), and a more recent overview is given by Franses (1997). This issue is of considerable importance as the distinction needs to be drawn between unit roots at the zero frequency, and unit roots at some or all of the seasonal frequencies in the case of non-annual data. An incorrect identification of the nature of such unit roots would lead to inappropriate filtering of the series prior to its use in regression analysis, say, as well as inadequate testing for possible cointegration between one such series and another.

A seasonal series is one which has a spectrum with distinct peaks at the seasonal frequencies, $\theta=$ $(2 \pi \mathrm{j} / \mathrm{s}), \mathrm{j}=1,2, \ldots . ., \mathrm{s}-1$, where $\mathrm{s}$ is the number of seasons in the year. The frequencies of interest with quarterly data, for example, are at $0,1 / 4,1 / 2$, and $3 / 4$ cycles, or $\theta=0, \pi / 2, \pi$, and $3 \pi / 2$. An integrated series is one that has an infinite mass in its spectrum at some frequency, $\theta$. In contrast, the spectrum of a stationary series is finite, but non-zero, at all frequencies. If a seasonal series has a unit root at all of its frequencies, it is said to be "seasonally integrated", or SI(s), and it needs to be s-differenced to make it stationary. Early contributions (e.g., Dickey et al., 1984) to the problem of testing for non-stationarity in seasonal time-series considered only a null of SI(s), and an alternative hypothesis of stationarity. That is, they did not consider the possibility of unit roots at only the seasonal (non-zero) frequencies, and neither did they allow for unit roots at a sub-set of the seasonal frequencies. The more recent test proposed by Kunst (1997) also falls into this category. In the case of quarterly data, this shortcoming was rectified partially by Osborne $e t$ al. (1988), and more fully with the tests proposed by Hylleberg et al. (1990) (hereafter "HEGY") and Ghysels et al. (1994). Franses (1991) and Beaulieu and Miron (1993) provided a similar testing framework for monthly data ${ }^{1}$.

Economic time-series data recorded only on a semi-annual basis are quite common. For example, many companies report their financial statements on this basis, at least on a provisional basis. The purpose of this paper is to investigate the properties of a HEGY testing framework in the case of semi-annual data, and to compare it with conventional Dickey-Fuller (1981) testing for unit roots at the zero frequency in such time-series. In the next section we describe the testing procedure, and section 3 discusses the asymptotic distributions of our test statistics. Section 4 deals with the finite-sample percentiles for these tests, and reports some small-sample power results. The 
application of the semi-annual HEGY tests is illustrated in section 5, and some concluding remarks and recommendations appear in section 6.

\section{A testing framework}

\subsection{Background}

In this section the framework for applying HEGY-type unit root tests is outlined for the case of semi-annual data. Recall the autoregressive model for a stochastic seasonal process, $x_{\mathrm{t}}$ :

$$
\Psi(B) x_{\mathrm{t}}=\varepsilon_{\mathrm{t}},
$$

where $\varepsilon_{\mathrm{t}} \sim \operatorname{iid}\left(0, \sigma^{2}\right), \Psi(B)$ is a polynomial in the backshift operator, B, and the roots of $\Psi(B)=0$ determine whether or not the series is stationary. For the purposes of the following derivation the data generating process of $\mathrm{x}_{\mathrm{t}}$ is assumed to be free of any deterministic components. Following HEGY (1990) and Beaulieu and Miron (1993), $\Psi(B)$ can be expressed in terms of elementary polynomials and a remainder:

$$
\Psi(B)=\sum_{k=1}^{2} \lambda_{k} \Delta(B) \frac{1-\delta_{k}(B)}{\delta_{k}(B)}+\Delta(B) \Psi^{*}(B),
$$

where $\quad \delta_{\mathrm{k}}(\mathrm{B})=1-\left(1 / \theta_{\mathrm{k}}\right) \mathrm{B} \mathrm{k}=1,2 ; \quad \Delta(B)=\prod_{k=1}^{p} \delta_{k}(B) ; \quad \lambda_{k}=\Psi\left(\theta_{k}\right) / \prod_{j=k} \delta_{j}\left(\theta_{k}\right)$;

and $\Psi^{*}(\mathrm{~B})$ is a remainder with roots outside the unit circle

The $\theta_{\mathrm{k}}$ 's are the unit roots. In the case of semi-annual data we have $\theta_{1}=1$ and $\theta_{2}=-1$, and so $\delta_{1}(\mathrm{~B})=(1-\mathrm{B}), \delta_{2}(\mathrm{~B})=(1+\mathrm{B})$, and $\Delta(\mathrm{B})=\left(1-\mathrm{B}^{2}\right)$. Substituting these into equation (2.2) yields:

$$
\Psi(B)=\lambda_{1}(B)(1+B)+\lambda_{2}(-B)(1-B)+\left(1-B^{2}\right) \Psi *(B) .
$$

Next, let $\pi_{1}=-\lambda_{1}$ and $\pi_{2}=-\lambda_{2}$, and substitute the right hand side of (2.3) into the autoregression equation $\Psi(B) x_{\mathrm{t}}=\varepsilon_{\mathrm{t}}$, so we have:

$$
-\pi_{1}(B)(1+B) x_{t}-\pi_{2}(-B)(1-B) x_{t}+\left(1-B^{2}\right) \Psi *(B) x_{t}=\varepsilon_{t} .
$$


This can be rewritten in the form of a regression equation on which the tests can be based:

$$
\Psi *(B) z_{3 t}=\pi_{1} z_{1 t-1}+\pi_{2} z_{2 t-1}+\varepsilon_{t},
$$

where:

$$
\begin{aligned}
& z_{1 t}=(1+B) x_{t}=x_{t}+x_{t-1} \\
& z_{2 t}=-(1-B) x_{t}=-\left(x_{t}-x_{t-1}\right) \\
& z_{3 t}=\left(1-B^{2}\right) x_{t}=x_{t}-x_{t-2} \\
& (\mathrm{t}=1,2,3, \ldots \ldots, \mathrm{n}) .
\end{aligned}
$$

\subsection{Implementation of the tests}

To apply the unit root tests with semi-annual data, equation (2.4) is estimated by Ordinary Least Squares (OLS). Using a 't-test', the null hypothesis of a unit root at the zero frequency $\left(\pi_{1}=0\right)$ is tested against the one-sided alternative hypothesis $\pi_{1}<0$, which is equivalent to testing $\Psi(1)=0$ versus the alternative of stationarity, $\Psi(1)>0$. Similarly, the hypothesis of a unit root at the $\pi$ frequency $\left(\pi_{2}=0\right)$ is tested against the alternative $\pi_{2}<0$. In addition, the 'F-statistic' for $\pi_{1}=\pi_{2}$ $=0$ may be used to test if unit roots exist at both frequencies simultaneously: that is, if the series is "seasonally integrated". The asymptotic and finite-sample percentiles of these non-standard ' $t$ ' and ' $F$ ' statistics are considered below, and various critical values are given in Table 2.

These tests are evaluated under the assumption that $\Psi^{*}(B)=1$. However, as Beaulieu and Miron (1993) point out, if $\Psi(B)$ is of order greater than $S$, then $\Psi^{*}(B) \neq 1$ and the fitted model must be "augmented" with lagged values of the dependent variable as extra regressors in order to whiten the errors. This follows from the findings of Said and Dickey (1984) in the context of the familiar (augmented) Dickey-Fuller (ADF) tests for unit roots at the zero frequency. These augmentations will introduce a finite-sample distortions in the null distributions of the ' $t$ ' and ' $F$ ' tests that will die out asymptotically, provided the correct number of lags is added. In particular, the number of such augmentation terms, q, must be allowed to increase as the sample size increases. Beaulieu and Miron (1990) investigated these finite-sample distortions in the case of monthly data, and found that the true sizes (significance levels) of the individual unit root ' $t$ ' tests were no higher than those implied by the asymptotic critical values. They therefore suggest that this distortion may cause under rejection of the unit root hypotheses in small samples with such data. 


\section{Asymptotic null distributions}

\subsection{HEGY-type tests for semi-annual data}

This section presents the asymptotic null distributions for the half-yearly data tests under consideration in this paper. Fuller (1976) proves that when $\rho=-1$, the limiting null distributions of $\hat{\rho}$ and the associated test statistics in a simple random walk model, a random walk with drift, and a random walk with drift and trend, are simply the mirror image of the limiting distributions when $\rho=1$ (Dickey and Fuller, 1979). Moreover, HEGY (1990) show that the analysis of Chan and Wei (1988) can be used to extract the asymptotic distribution theory for the HEGY ' $t$ ' tests from the results of Dickey and Fuller (1979) and Fuller (1976).

The asymptotic null distributions for our two ' $t$ ' statistics follow directly from the analyses ${ }^{3}$ of HEGY (1990) and of Beaulieu and Miron (1993). The latter provide the derivation of the asymptotic distributions under the assumption that $\varepsilon_{t}$ is a martingale difference ${ }^{2}$ sequence with constant variance. A sequence of random scalars, $\left\{\varepsilon_{t},\right\}_{t=1}^{\infty}$, is a martingale difference sequence if $\mathrm{E}\left(\varepsilon_{\mathrm{t}}\right)=0$ for all $\mathrm{t}$ and $\mathrm{E}\left(\varepsilon_{\mathrm{t}} \mid \varepsilon_{\mathrm{t}-1}, \ldots, \varepsilon_{1}\right)=0$ for $\mathrm{t}=2,3, \ldots \ldots, \mathrm{n}$. (Hamilton, 1994, p.189).

When the unit root tests are applied in the context of a regression model without any deterministic terms the statistic $t_{1}$ has the same limiting null distribution as the familiar Dickey-Fuller (DF) ' $t$ test' statistic:

$$
\mathrm{t}_{1} \stackrel{L}{\longrightarrow} \frac{\left(\int_{0}^{1}\left[W_{1}(r)\right]^{2} d W_{1}\right)}{\left(\int_{0}^{1}\left[W_{1}(r)\right]^{2} d r\right)^{1 / 2}}=\frac{\frac{1}{2}\left\{[W(1)]^{2}-1\right\}}{\left\{\int_{0}^{1}[W(r)]^{2} d r\right\}^{1 / 2}},
$$

where $\mathrm{W}(\mathrm{r})$ denotes a standard Brownian motion and $\int_{0}^{1}$ is a stochastic integral (Ghysels et al., 1994; Hamilton, 1994). Further, the asymptotic null distribution of $t_{2}$ is the mirror image of the usual DF distribution; that is, the negative of the $t_{2}$ has the asymptotic distribution in (3.1). Essentially, these results follow from the fact that $z_{1 t}$ and $z_{2 t}$ in equation (2.5) are asymptotically uncorrelated.

Ghysels, et al.(1994) show that this relationship with the usual DF 't-tests' also holds in finite samples. By the same arguments, this will also be true for semi-annual data. Further, from the results of Engle, Granger, Hylleberg and Lee (1993), they prove that for quarterly seasonal data 
the asymptotic null distributions for 'F' statistics for testing either (i) that the series is seasonally integrated; or (ii) that there are unit roots at all seasonal frequencies; are the same as the limiting distributions of the sum of the appropriate squared 't-statistics'. Similarly, the asymptotic null distribution of our $F_{12}$ statistic, for seasonally integrated half-yearly data, follows directly from the limiting distributions of the sum of the squares of $t_{1}$ and $t_{2}$. So, in the case of no drift, no trend, and no seasonal dummy variable in the fitted regression we have:

$$
\mathbf{F}_{12} \stackrel{L}{\longrightarrow} \frac{1}{2}\left\{\frac{\left(\int_{0}^{1}\left[W_{1}(r)\right]^{2} d W_{1}\right)^{2}}{\left(\int_{0}^{1}\left[W_{1}(r)\right]^{2} d r\right)}+\frac{\left(\int_{0}^{1}\left[W_{2}(r)\right]^{2} d W_{2}\right)^{2}}{\left(\int_{0}^{1}\left[W_{2}(r)\right]^{2} d r\right)}\right\},
$$

where $\mathrm{W}_{\mathrm{i}}(\mathrm{r})$ for $\mathrm{i}=1,2$ denote independent standard Brownian motions (Ghysels, et al., 1994).

Next, consider the asymptotic null distributions of the tests when deterministic terms are added to the fitted regression equation, (2.4). The general effects of the various deterministic terms are discussed and then the actual distributions are presented following the notation of Beaulieu and Miron (1993). The addition of drift or trend terms affects the asymptotic null distribution of $t_{1}$ because these components have their spectral mass at the zero frequency (HEGY, 1990). However, the asymptotic distribution of $\mathrm{t}_{2}$ is independent of the drift and trend terms as $\mathrm{z}_{2 \mathrm{t}}$ is asymptotically orthogonal to terms that are not periodic (Beaulieu and Miron, 1993). Recall that the asymptotic distribution of the $F_{12}$ statistic is related to those of the squared $t_{1}$ and squared $t_{2}$ statistics. Thus, the asymptotic null distribution of the $\mathrm{F}_{12}$ statistic will also change with the addition of deterministic terms, as the distribution of $t_{1}$ changes when a drift and/or trend is added to the fitted regression.

In the case of the ' $t$ ' statistics, the effect of adding a seasonal dummy variable into the "HEGY regression" is the reverse of that of adding constant and trend components. Once a constant term is included in the regression, the addition of a seasonal dummy variable does not affect the asymptotic null distribution of $t_{1}$ any further. The subsequent addition of a seasonal dummy variable does, however, change the asymptotic null distribution of $t_{2}$, and so the asymptotic properties of $\mathrm{F}_{12}$ also change in this case. Again, this all follows for reasons analogous to those in the case of quarterly data. Some further insights into these, and other relationships between the tests, in case of quarterly data are given by Smith and Taylor (1998). 
The forms of the various asymptotic distributions can now be summarized. Let the distributions of $t_{1}$ and $t_{2}$ when deterministic terms are excluded from the regression equation be denoted as:

$$
\mathrm{t}_{1} \stackrel{L}{\longrightarrow} \frac{N_{1}^{0}}{D_{1}^{0}} \quad ; \quad \mathrm{t}_{2} \stackrel{L}{\longrightarrow} \frac{N_{2}^{0}}{D_{2}^{0}}
$$

Following the notation of Beaulieu and Miron (1993) $\mathrm{N}_{1}{ }^{\mathrm{x}}$ and $\mathrm{N}_{2}{ }^{\mathrm{x}}$ represent the part of the numerator that differs from that in the above $t_{1}$ and $t_{2}$ distributions, respectively. Similarly $D_{1}{ }^{x}$ and $\mathrm{D}_{2}{ }^{\mathrm{x}}$ represent the part of the denominator that differs. The four variations of deterministic terms in the fitted regression model are represented by $x=\mu, \tau, \xi$, and $\xi \tau$, corresponding to regressions with a constant, a constant and trend, a constant and seasonal dummy, and finally a constant, trend and seasonal dummy. Thus, the general form of the limiting null distributions for the 't-statistics' can be written as:

$$
\begin{gathered}
\mathrm{t}_{1} \stackrel{L}{\longrightarrow} \frac{\left(\int_{0}^{1}\left[W_{1}(r)\right]^{2} d W_{1}\right)^{2}+N_{1}^{X}}{\left(\int_{0}^{1}\left[W_{1}(r)\right]^{2} d r+D_{1}^{X}\right)^{1 / 2}} \\
\mathrm{t}_{2} \stackrel{L}{\longrightarrow} \frac{\left(\int_{0}^{1}\left[W_{2}(r)\right]^{2} d W_{2}\right)^{2}+N_{2}^{X}}{\left(\int_{0}^{1}\left[W_{2}(r)\right]^{2} d r+D_{2}^{X}\right)^{1 / 2}} .
\end{gathered}
$$

The five possible asymptotic null distributions for each of the test statistics are summarized in Table 1. Only the parts of the numerator and denominator that differ from the no-drift, no-trend model, are given for the ' $\mathrm{t}$ ' statistics. This is done to provide visual representation of the distributions that are the same. The full asymptotic null distribution of the $F_{12}$ statistic is given in terms of these components.

\section{[Table 1 About Here]}

\subsection{Dickey-Fuller tests and semi-annual data}

Several properties of the Dickey-Fuller 't-test' have been analyzed in the context of seasonal data. For example, HEGY (1990) showed it to have asymptotic equivalence to their $\mathrm{t}_{1}$ statistic in the "no drift/no trend" case. Ghysels, et al. (1994) demonstrated that when unit roots exist at seasonal frequencies the Dickey-Fuller 't-test' is still a valid test for unit roots at the zero frequency, provided the usual DF regression is appropriately "augmented" with $l \geq \mathrm{s}-1$ lagged values of the 
differenced series. They use Monte Carlo simulations to see how the existence of seasonal unit roots influences the finite-sample size and power of the test. Their results show that, in the case of quarterly data, when $l<\mathrm{s}-1$ the size of the DF test is severely distorted. When $l \geq \mathrm{s}-1$ the size is close to its nominal size, provided the data generating process is free of negative moving average components.

Although we have not explicitly explored these characteristics of the DF 't-test' in the context of semi-annual data here, intuitively it is clear that corresponding results to those above will hold (with $\mathrm{s}=2$ ).

\subsection{Moving-average errors}

Although the HEGY test provides for identification of roots at different frequencies, it has been found to suffer from size distortions from negative MA components in the data generating process. In particular, for the data generating process:

$$
Y_{\mathrm{t}}=\alpha_{\mathrm{d}} Y_{t-d}+u_{\mathrm{t}}
$$

where $u_{\mathrm{t}}=\varepsilon_{\mathrm{t}}+\theta_{1} \varepsilon_{\mathrm{t}-1}+\theta_{4} \varepsilon_{\mathrm{t}-4}$, and $\theta_{1}=-0.9$, the near cancellation of $(1-\mathrm{B})$ in the autoregressive component of $u_{t}$ makes the unit root at the zero frequency difficult to detect. This also explains why the Dickey-Fuller test suffers from size distortions with negative MA components, because it has the same distribution as the HEGY $\mathrm{t}_{1}$ test when $l \geq \mathrm{s}-1$. This is not a trivial problem as such situations arise frequently in practice.

A large bias in size or very low power was also found to occur when seasonal dummies are in the data generating process, but are not included in the regression. This provides justification for including deterministic terms or additional lags even though they may be irrelevant and thus may reduce the power of the test.

\section{Finite-sample results}

\subsection{Critical Values}

We have investigated the small-sample distributions of our three semi-annual unit root tests under both the null and alternative hypotheses using Monte Carlo simulations. All of these simulations 
were implemented using SHAZAM (1997) on a DEC Alpha 3000 workstation. The data generating process used was $x_{t}=x_{t-2}+\varepsilon_{t}$, where the $\varepsilon_{t}$ values were generated by the normal random number generator in SHAZAM. Five different variations of the basic HEGY auxiliary regression were fitted to the generated data: drift, seasonal dummy variable, and trend (D,S,T); drift, seasonal dummy, and no trend (D,S,NT); drift, no seasonal dummy variable, and trend (D,NS,T); drift, no seasonal dummy variable, and no trend (D,NS,NT); and no drift, no seasonal dummy variable, and no trend (ND, NS, NT).

The initial value for $y_{t}$ was set to zero and then the first 200 observations were dropped to "wash out" the effect of this initial value. All simulations were based on 20,000 repetitions. Critical values associated with the $1^{\text {st }}, 5^{\text {th }}$ and $10^{\text {th }}$ percentiles of the underlying distributions were generated for the ' $t_{1}$ test' of $\mathrm{H}_{0}: \pi_{1}=0$ and for the ' $\mathrm{t}_{2}$ test' of $\mathrm{H}_{0}: \pi_{2}=0$. Corresponding critical values were calculated for the ' $\mathrm{F}_{12}$ test' of $\mathrm{H}_{0}: \pi_{1}=\pi_{2}=0$ by determining the $90^{\text {th }}, 95^{\text {th }}$, and $99^{\text {th }}$ percentiles of the empirical distributions. These results are presented in Table 2.

\section{[Table 2 About Here]}

There is no discernable change in the $t_{2}$ critical values when a drift and/or trend are added to the fitted regressions, as was indicated by the asymptotic distribution theory in the previous section. In contrast, the critical values for $t_{1}$ change when either a drift or trend is added to the fitted model on which the tests are based. The subsequent addition of a seasonal dummy variable does not then change the finite sample distribution of $t_{1}$, but it does change that of $t_{2}$. As predicted by the asymptotic distribution theory, the ' $\mathrm{F}_{12}$ statistic' critical values change with each variation to the deterministic components in the fitted regression, as its distribution is the same as the distribution of the sum of the squares of $t_{1}$ and $t_{2}$.

It is also worth noting the very close accordance between the no-drift, no-trend values for $t_{1}$ in Table 2, the corresponding Dickey-Fuller (DF) critical values of MacKinnon (1991), and the HEGY (1990) $\pi_{1}$ values. For example, with a $10 \%$ significance level and $n=200$, the critical values are -1.6163 in Table 2, -1.6165 from MacKinnon, and -1.62 from HEGY. The critical values for $\mathrm{t}_{2}$ (i.e., for testing $\mathrm{H}_{0}: \pi_{2}=0$ ) in Table 2 can be compared with the HEGY (1990) critical values for the fitted model with no deterministic terms. For the $10 \%$ level and $n=200$ the two statistics are -1.6112 and -1.61 respectively. 
The results in Table 2 are based on a data generating process (d.g.p.) of $x_{t}=x_{t-2}+\varepsilon_{t}$. That is, unit roots are present at both the zero and $\pi$ frequencies - the semi-annual series is "seasonally integrated". An alternative approach is to consider a data generating process that has a unit root at only one of these frequencies, but then still base the unit roots tests on the HEGY-type integrating regression as in equation (2.4). Critical values were also generated for these tests. In the test for a unit root only at the zero frequency, a simple random walk was used as the d.g.p.; in the second case the d.g.p. had a unit root at the $\pi$ frequency but not at the zero frequency. For completeness, these results appear in Table 3.

\section{[Table 3 About Here]}

\subsection{Powers of the tests}

The Monte Carlo experiment was also used to simulate the size-adjusted powers of the test statistics developed in this paper, for the following three fitted regressions: drift, seasonal dummy variable, and trend (D, S, T); drift, seasonal dummy variable, and no trend (D, S, NT); drift, no seasonal dummy, with trend (D, NS, T).

Using the d.g.p. of Table 2, namely $x_{t}=\rho x_{t-2}+\varepsilon_{t}$, the size-adjusted powers of the tests of $\pi_{1}=0$, $\pi_{2}=0$ and $\pi_{1}=\pi_{2}=0$, were simulated for $\rho=[0.0(0.1) 1.0]$ and various sample sizes (n). Each power curve was generated using 20,000 repetitions. The results of these empirical power simulations for the $t_{1}, t_{2}$, and $F_{12}$ tests are given in Tables 4-6, for the case where the d.g.p. is as in Table 2; and in Tables 7 and 8 for the case where the d.g.p. is as in Table 3. Illustrative plots appear in Figures 1-3 and Figures 4 and 5 respectively.

\section{[Tables 4 to 8 About Here]}

These results show that the power curves for large sample sizes have the basic expected shape. That is, they move towards $100 \%$ as $\rho$ moves away from 1 . There is reasonable power when $\mathrm{n}=$ 100 , but very low size-adjusted power when the sample size is small. This is no surprise given other results for similar such unit root tests. The patterns in the results as the sample size is increased reflect the consistency of the tests. Changing the significance level of the test yields the usual tradeoff between the size and power. As expected, the tests based on auxiliary regressions 
without a drift or trend have more power than their counterparts with deterministic terms, because the data generating process does not include deterministic terms.

\section{[Figures 1 to 5 About Here]}

\section{Some applications}

The application of the testing procedures discussed in this paper is illustrated here for four quite different semi-annual economic time-series. In each case, we compare the results obtained when the possibility of seasonal unit roots is entertained, with those obtained when the ADF tests are used to test for unit roots only at the zero frequency. The series are published only in semiannual form, and are:

(i) New Zealand total knitted fabric sales (tonnes), June 1965 to December 1997, series SEPH.SATTD (Statistics New Zealand, 1998);

(ii) Canadian pre-cast concrete price index, (1981=100), 1977 to 1992, matrix 421 (Statistics Canada, 1998);

(iii) Canadian production of marketable gas (millions of cubic meters, oil-equivalent), June 1979 to December 1989 (Petroleum Monitoring Agency Canada, various years);

(iv) U.S.A. six-monthly increase in number of cellular phone subscribers, December 1984 to December 1995 (Waterman, 1998).

These series are shown ${ }^{7}$ in Figure 6, and Table 9 presents the results of testing for a unit root only at the zero frequency, using the ADF tests. We allowed for drift and/or trend in the ADF regressions, and used the strategy of Dolado et al. (1990) to determine their final inclusion ${ }^{4}$. The "augmentation level", q, for the regressions was chosen as the minimum required to obtain "clean" autocorrelation and partial autocorrelation functions for the associated residuals ${ }^{5}$; and a seasonal dummy variable was included with any drift term ${ }^{6}$. As can be seen, the ADF tests suggest in each case that the series are I(1). Accordingly, one would infer that the series can be made stationary via simple first-differencing.

In Table 10 we show the results of applying the semi-annual HEGY tests outlined in this paper. In the cases (i), (iii) and (iv) we find that in fact the series are SI(1) - that is, they each have unit roots at both the zero and $\pi$ frequencies. So, in fact two-period differencing is the appropriate filter needed to make these series stationary. The earlier conclusion that series (ii) has a unit root 
(only) at the zero frequency is upheld in Table 10, but these examples certainly illustrate the need for care when applying standard ADF tests to semi-annual data.

\section{[Figure 6 About Here]}

\section{[Tables 9 and 10 About Here]}

\section{Conclusions}

In this paper we have discussed a framework for testing for unit roots in time-series data that are reported at a maximum frequency of twice a year. In such cases, the possibility of unit roots at the zero and/or $\pi$ frequencies arises, and the testing strategies developed by Hylleberg et al. (1990) and Beaulieu and Miron (1993) provide a natural framework to exploit. The asymptotic null distributions of the tests we propose are derived, discussed and summarized, and in certain cases they can be linked to existing results associated with the well-known tests of Dickey and Fuller $(1979,1981)$. Simulated percentiles for the finite-sample null distributions of the test statistics are tabulated for various sample sizes and combinations of deterministic terms in the fitted regressions. The powers of the tests are simulated under a similar range of situations, and their application is illustrated with several actual semi-annual time-series.

The analysis in this paper may be extended in several directions. The obvious one is to investigate the properties of corresponding tests for cointegration. Other topics of interest include the size-robustness of the tests to autocorrelation in the data-generating process; to the method used to select an appropriate "augmentation level"; and to structural breaks in the data. These remain matters for future research.

\section{Acknowledgements}

The authors are grateful to Robert Draeseke, Judith Giles, Nilanjana Roy, Gugsa Werkneh and participants in the University of Victoria Econometrics Colloquium, for their helpful comments on an earlier version of this work. 
Table 1

Effects of deterministic terms on asymptotic distributions of semi-annual unit root tests

\begin{tabular}{|c|c|c|c|}
\hline Model & $\mathbf{t}_{1}$ & $\mathbf{t}_{2}$ & $\mathbf{F}_{12}$ \\
\hline $\begin{array}{l}\text { ND, NT, } \\
\text { NS }\end{array}$ & $\frac{N_{1}^{0}}{D_{1}^{0}}$ & $\frac{N_{2}^{0}}{D_{2}^{0}}$ & $\frac{N_{12}^{0}}{D_{12}^{0}}=\left(\frac{N_{1}^{0}}{D_{1}^{0}}\right)^{2}+\left(\frac{N_{2}^{0}}{D_{2}^{0}}\right)^{2}$ \\
\hline \multirow[t]{2}{*}{$\begin{array}{l}\text { D, NT, } \\
\text { NS }\end{array}$} & $N_{1}^{\mu}=-W_{1}(1) \int_{0}^{1} W_{1}(1) d r$ & $N_{2}^{\mu}=0$ & \multirow[t]{2}{*}{$\left(\frac{\left(\int_{0}^{1}\left[W_{1}(r)\right]^{2} d W_{1}\right)^{2}+N_{1}^{\mu}}{\left(\int_{0}^{1}\left[W_{1}(r)\right]^{2} d r+D_{1}^{\mu}\right)^{1 / 2}}\right)^{2}+\left(\frac{N_{2}^{0}}{D_{2}^{0}}\right)^{2}$} \\
\hline & $D_{1}^{\mu}=-\left(\int_{0}^{1} W_{1}(1) d r\right)^{2}$ & $D_{2}^{\mu}=0$ & \\
\hline \multirow[t]{2}{*}{$\mathrm{D}, \mathrm{T}, \mathrm{NS}$} & $\begin{array}{l}N_{1}^{\tau}=-4 W_{1}(1) \int_{0}^{1} W_{1}(r) d r \\
+6 \int_{0}^{1} W_{1}(r) d r \int_{0}^{1} r d W_{1}(r) \\
-12 \int_{0}^{1} r W_{1}(r) d r \int_{0}^{1} r d W_{1}(r) \\
+6 W_{1}(1) \int_{0}^{1} r W_{1}(r) d r\end{array}$ & $N_{2}^{\tau}=0$ & \multirow[t]{2}{*}{$\left(\frac{\left(\int_{0}^{1}\left[W_{1}(r)\right]^{2} d W_{1}\right)^{2}+N_{1}^{\tau}}{\left(\int_{0}^{1}\left[W_{1}(r)\right]^{2} d r+D_{1}^{\tau}\right)^{1 / 2}}\right)^{2}+\left(\frac{N_{2}^{0}}{D_{2}^{0}}\right)^{2}$} \\
\hline & $\begin{array}{l}D_{1}^{\tau}=-4\left(\int_{0}^{1} W_{1}(r) d r\right)^{2}-12\left(\int_{0}^{1} r W_{1}(r) d r\right)^{2} \\
+12 \int_{0}^{1} W_{1}(r) d r \int_{0}^{1} r W_{1}(r) d r\end{array}$ & $D_{2}^{\tau}=0$ & \\
\hline \multirow[t]{2}{*}{$\mathrm{D}, \mathrm{NT}, \mathrm{S}$} & $N_{1}^{\xi}=N_{1}^{\mu}$ & $N_{2}^{\xi}=-W_{2}(1) \int_{0}^{1} W_{2}(1) d r$ & \multirow{2}{*}{$\begin{array}{l}\left(\frac{\left(\int_{0}^{1}\left[W_{1}(r)\right]^{2} d W_{1}\right)^{2}+N_{1}^{\mu}}{\left(\int_{0}^{1}\left[W_{1}(r)\right]^{2} d r+D_{1}^{\mu}\right)^{1 / 2}}\right)^{2}+ \\
\left(\frac{\left(\int_{0}^{1}\left[W_{2}(r)\right]^{2} d W_{2}\right)^{2}+N_{2}^{\xi}}{\left(\int_{0}^{1}\left[W_{2}(r)\right]^{2} d r+D_{2}^{\xi}\right)^{1 / 2}}\right)^{2}\end{array}$} \\
\hline & $D_{1}^{\xi}=D_{1}^{\mu}$ & $D_{2}^{\xi}=-\left(\int_{0}^{1} W_{2}(1) d r\right)^{2}$ & \\
\hline \multirow[t]{2}{*}{$\mathrm{D}, \mathrm{T}, \mathrm{S}$} & $N_{1}^{\xi \tau}=N_{1}^{\tau}$ & $N_{2}^{\xi \tau}=N_{2}^{\xi}$ & \multirow{2}{*}{$\begin{array}{l}\left(\frac{\left(\int_{0}^{1}\left[W_{1}(r)\right]^{2} d W_{1}\right)^{2}+N_{1}^{\tau}}{\left(\int_{0}^{1}\left[W_{1}(r)\right]^{2} d r+D_{1}^{\tau}\right)^{1 / 2}}\right)^{2}+ \\
\left(\frac{\left(\int_{0}^{1}\left[W_{2}(r)\right]^{2} d W_{2}\right)^{2}+N_{2}^{\xi}}{\left(\int_{0}^{1}\left[W_{2}(r)\right]^{2} d r+D_{2}^{\xi}\right)^{1 / 2}}\right)^{2}\end{array}$} \\
\hline & $D_{1}^{\xi \tau}=D_{1}^{\tau}$ & $D_{2}^{\xi \tau}=D_{2}^{\xi}$ & \\
\hline
\end{tabular}


Table 2

Critical values for the HEGY-type unit root tests. d.g.p.: $\left(1-\mathrm{B}^{2}\right) \mathrm{x}_{\mathrm{t}}=\varepsilon_{\mathrm{t}}$

\begin{tabular}{|c|c|c|c|c|c|c|c|c|c|c|}
\hline \multirow[t]{2}{*}{ Model } & \multirow[b]{2}{*}{$\mathbf{n}$} & \multicolumn{3}{|c|}{$\pi_{1}=0$} & \multicolumn{3}{|c|}{$\pi_{2}=0$} & \multicolumn{3}{|c|}{$\pi_{1}=\pi_{2}=0$} \\
\hline & & $1 \%$ & $5 \%$ & $10 \%$ & $1 \%$ & $5 \%$ & $10 \%$ & $99 \%$ & $95 \%$ & $90 \%$ \\
\hline \multicolumn{11}{|l|}{$\mathrm{D}, \mathrm{S}, \mathrm{T}$} \\
\hline & 20 & -4.3597 & -3.5654 & -3.1873 & -3.7030 & -2.9599 & -2.5935 & 14.9449 & 9.8711 & 7.9402 \\
\hline & 50 & -4.1381 & -3.4776 & -3.1532 & -3.5644 & -2.8922 & -2.5810 & 11.6604 & 8.6479 & 7.3220 \\
\hline & 100 & -4.0264 & -3.4291 & -3.1358 & -3.4967 & -2.8749 & -2.5732 & 11.2051 & 8.3778 & 7.1243 \\
\hline & 200 & -4.0109 & -3.4256 & -3.1286 & -3.4846 & -2.9005 & -2.5823 & 10.8262 & 8.2567 & 7.0817 \\
\hline & 5000 & -4.0210 & -3.4664 & -3.1760 & -3.4046 & -2.8280 & -2.5373 & 10.4656 & 8.1290 & 7.0575 \\
\hline & 10000 & -4.0463 & -3.4625 & -3.1837 & -3.3761 & -2.8242 & -2.5255 & 10.6561 & 8.2164 & 7.0964 \\
\hline \multicolumn{11}{|l|}{$\mathrm{D}, \mathrm{S}, \mathrm{NT}$} \\
\hline & 20 & -3.6986 & -2.9087 & -2.5561 & -3.7253 & -2.9347 & -2.5807 & 11.5547 & 7.7163 & 6.1039 \\
\hline & 50 & -3.5143 & -2.8779 & -2.5713 & -3.5388 & -2.8887 & -2.5741 & 9.5589 & 6.9001 & 5.7132 \\
\hline & 100 & -3.4461 & -2.8687 & -2.5585 & -3.4909 & -2.8738 & -2.5714 & 9.2908 & 6.7591 & 5.6672 \\
\hline & 200 & -3.4391 & -2.8578 & -2.5643 & -3.4787 & -2.9034 & -2.5850 & 9.0919 & 6.7064 & 5.5854 \\
\hline & 5000 & -3.4903 & -2.9109 & -2.5926 & -3.4038 & -2.8276 & -2.5375 & 8.6661 & 6.5033 & 5.5156 \\
\hline & 10000 & -3.4773 & -2.8959 & -2.6009 & -3.3763 & -2.8243 & -2.5256 & 8.7691 & 6.5342 & 5.5520 \\
\hline \multicolumn{11}{|l|}{$\mathrm{D}, \mathrm{NS}, \mathrm{T}$} \\
\hline & 20 & -4.2762 & -3.4796 & -3.1092 & -2.5974 & -1.7879 & -1.4403 & 11.5195 & 7.5930 & 6.0760 \\
\hline & 50 & -4.1008 & -3.4568 & -3.1371 & -2.5615 & -1.8881 & -1.5436 & 9.6565 & 6.8921 & 5.7726 \\
\hline & 100 & -4.0231 & -3.4295 & -3.1281 & -2.5731 & -1.9098 & -1.5720 & 9.2573 & 6.8333 & 5.7206 \\
\hline & 200 & -3.9998 & -3.4220 & -3.1246 & -2.5131 & -1.9334 & -1.6107 & 8.8741 & 6.7787 & 5.6860 \\
\hline & 5000 & -4.0211 & -3.4659 & -3.1765 & -2.4668 & -1.8768 & -1.5657 & 8.8779 & 6.8213 & 5.8105 \\
\hline & 10000 & -4.0463 & -3.4628 & -3.1838 & -2.5147 & -1.8792 & -1.5568 & 9.0445 & 6.8076 & 5.8415 \\
\hline \multicolumn{11}{|l|}{$\mathrm{D}, \mathrm{NS}, \mathrm{NT}$} \\
\hline & 20 & -3.6524 & -2.8802 & -2.5381 & -2.6349 & -1.8600 & -1.4787 & 8.7567 & 5.6446 & 4.4119 \\
\hline & 50 & -3.5091 & -2.8748 & -2.5667 & -2.5841 & -1.9209 & -1.5578 & 7.3945 & 5.2131 & 4.2230 \\
\hline & 100 & -3.4477 & -2.8775 & -2.5592 & -2.5794 & -1.9143 & -1.5798 & 7.3461 & 5.1094 & 4.1850 \\
\hline & 200 & -3.4490 & -2.8577 & -2.5624 & -2.5216 & -1.9385 & -1.6111 & 7.2181 & 5.1364 & 4.1707 \\
\hline & 5000 & -3.4906 & -2.9113 & -2.5927 & -2.4656 & -1.8770 & -1.5657 & 6.9546 & 5.0897 & 4.1968 \\
\hline & 10000 & -3.4772 & -2.8956 & -2.6007 & -2.5147 & -1.8791 & -1.5567 & 7.0410 & 5.0871 & 4.1873 \\
\hline \multicolumn{11}{|l|}{ ND, NS, NT } \\
\hline & 20 & -2.7309 & -1.9283 & -1.5399 & -2.7428 & -1.9265 & -1.5310 & 6.0730 & 3.6772 & 2.7541 \\
\hline & 50 & -2.6158 & -1.9105 & -1.5636 & -2.6117 & -1.9351 & -1.5661 & 5.3603 & 3.3859 & 2.5819 \\
\hline & 100 & -2.6042 & -1.9164 & -1.5943 & -2.5846 & -1.9196 & -1.5866 & 5.0504 & 3.2839 & 2.5656 \\
\hline & 200 & -2.5915 & -1.9499 & -1.6163 & -2.5291 & -1.9404 & -1.6112 & 6.0312 & 3.6146 & 2.7172 \\
\hline & 5000 & -2.6200 & -1.9774 & -1.6621 & -2.4661 & -1.8767 & -1.5657 & 4.9073 & 3.2119 & 2.5234 \\
\hline & 10000 & -2.6273 & -1.9975 & -1.6690 & -2.5145 & -1.8792 & -1.5567 & 4.8699 & 3.2301 & 2.5243 \\
\hline
\end{tabular}


Table 3

Critical values for the individual seasonal unit root tests

$$
\text { d.g.p.: }(1-B) x_{t}=\varepsilon_{t} \quad \text { d.g.p.: }(1+B) x_{t}=\varepsilon_{t}
$$

\begin{tabular}{|c|c|c|c|c|c|c|c|}
\hline \multirow[t]{2}{*}{ Model } & \multirow[b]{2}{*}{$\mathbf{N}$} & \multicolumn{3}{|c|}{$\pi_{1}=\mathbf{0}$} & \multicolumn{3}{|c|}{$\pi_{2}=\mathbf{0}$} \\
\hline & & $1 \%$ & $5 \%$ & $10 \%$ & $1 \%$ & $5 \%$ & $10 \%$ \\
\hline \multicolumn{8}{|l|}{$\mathrm{D}, \mathrm{S}, \mathrm{T}$} \\
\hline & 20 & -4.5573 & -3.6889 & -3.2840 & -3.7952 & -2.9836 & -2.6175 \\
\hline & 50 & -4.1575 & -3.5107 & -3.1967 & -3.5812 & -2.8933 & -2.5852 \\
\hline & 100 & -4.0394 & -3.4492 & -3.1518 & -3.5009 & -2.8949 & -2.5741 \\
\hline & 200 & -4.0077 & -3.4346 & -3.1314 & -3.5119 & -2.9053 & -2.5844 \\
\hline & 5000 & -4.0074 & -3.4647 & -3.1744 & -3.4046 & -2.8304 & -2.5388 \\
\hline & 10000 & -4.0408 & -3.4647 & -3.1822 & -3.3689 & -2.8246 & -2.5250 \\
\hline \multicolumn{8}{|l|}{$\mathrm{D}, \mathrm{S}, \mathrm{NT}$} \\
\hline & 20 & -3.7920 & -2.9720 & -2.6209 & -3.7809 & -3.0182 & -2.6364 \\
\hline & 50 & -3.5273 & -2.9010 & -2.5920 & -3.5849 & -2.9001 & -2.5903 \\
\hline & 100 & -3.4967 & -2.8749 & -2.5696 & -3.5092 & -2.8979 & -2.5790 \\
\hline & 200 & -3.4686 & -2.8608 & -2.5611 & -3.5123 & -2.9051 & -2.5885 \\
\hline & 5000 & -3.4745 & -2.9079 & -2.5920 & -3.4036 & -2.8308 & -2.5390 \\
\hline & 10000 & -3.4758 & -2.8964 & -2.6018 & -3.3691 & -2.8247 & -2.5252 \\
\hline \multicolumn{8}{|l|}{$\mathrm{D}, \mathrm{NS}, \mathrm{T}$} \\
\hline & 20 & -4.5285 & -3.6806 & -3.2892 & -2.6241 & -1.8378 & -1.4749 \\
\hline & 50 & -4.1618 & -3.5155 & -3.2006 & -2.5660 & -1.9044 & -1.5534 \\
\hline & 100 & -4.0525 & -3.4448 & -3.1542 & -2.5878 & -1.9164 & -1.5787 \\
\hline & 200 & -4.0103 & -3.4370 & -3.1307 & -2.5088 & -1.9405 & -1.6174 \\
\hline & 5000 & -4.0074 & -3.4642 & -3.1746 & -2.4541 & -1.8796 & -1.5657 \\
\hline & 10000 & -4.0411 & -3.4643 & -3.1821 & -2.5170 & -1.8804 & -1.5566 \\
\hline \multicolumn{8}{|l|}{$\mathrm{D}, \mathrm{NS}, \mathrm{NT}$} \\
\hline & 20 & -3.7839 & -2.9961 & -2.6377 & -2.7150 & -1.8909 & -1.5147 \\
\hline & 50 & -3.5449 & -2.9164 & -2.6002 & -2.5933 & -1.9269 & -1.5708 \\
\hline & 100 & -3.4896 & -2.8807 & -2.5719 & -2.6030 & -1.9253 & -1.5859 \\
\hline & 200 & -3.4728 & -2.8623 & -2.5638 & -2.5151 & -1.9440 & -1.6178 \\
\hline & 5000 & -3.4745 & -2.9074 & -2.5918 & -2.4543 & -1.8797 & -1.5656 \\
\hline & 10000 & -3.4757 & -2.8967 & -2.6014 & -2.5171 & -1.8805 & -1.5566 \\
\hline \multicolumn{8}{|l|}{ ND, NS, NT } \\
\hline & 20 & -2.7678 & -1.9597 & -1.5652 & -2.7994 & -1.9621 & -1.5620 \\
\hline & 50 & -2.6501 & -1.9284 & -1.5774 & -2.6260 & -1.9524 & -1.5868 \\
\hline & 100 & -2.6190 & -1.9283 & -1.6007 & -2.6156 & -1.9335 & -1.5918 \\
\hline & 200 & -2.6011 & -1.9519 & -1.6247 & -2.5143 & -1.9463 & -1.6194 \\
\hline & 5000 & -2.6332 & -1.9771 & -1.6620 & -2.4545 & -1.8796 & -1.5656 \\
\hline & 10000 & -2.6241 & -1.9972 & -1.6697 & -2.5169 & -1.8806 & -1.5567 \\
\hline
\end{tabular}


Table 4

Power of the $t_{1}$ test. d.g.p.: $\left(1-B^{2}\right) x_{t}=\varepsilon_{t}$

\begin{tabular}{|c|c|c|c|c|c|c|c|c|c|c|c|}
\hline$\rho$ & 1.00 & 0.90 & 0.80 & 0.70 & 0.60 & 0.50 & 0.40 & 0.30 & 0.20 & 0.10 & 0.00 \\
\hline \multicolumn{12}{|l|}{$\mathrm{D}, \mathrm{S}, \mathrm{T}$} \\
\hline \multicolumn{12}{|c|}{$1 \%$} \\
\hline$n=20$ & 1.00 & 1.44 & 1.46 & 1.86 & 2.43 & 2.84 & 3.99 & 5.80 & 8.28 & 11.71 & 18.17 \\
\hline$n=50$ & 1.00 & 1.28 & 2.05 & 3.61 & 7.09 & 12.93 & 24.56 & 41.94 & 61.44 & 79.63 & 92.04 \\
\hline$n=100$ & 1.00 & 1.96 & 5.88 & 17.41 & 41.18 & 71.77 & 91.67 & 99.07 & 99.91 & 100.00 & 100.00 \\
\hline \multicolumn{12}{|c|}{$5 \%$} \\
\hline$n=20$ & 5.00 & 5.83 & 6.63 & 7.42 & 9.31 & 11.73 & 14.72 & 19.55 & 26.65 & 33.98 & 44.89 \\
\hline$n=50$ & 5.00 & 6.26 & 8.92 & 15.43 & 26.00 & 40.87 & 59.31 & 77.72 & 90.12 & 96.65 & 99.27 \\
\hline$n=100$ & 5.00 & 9.06 & 22.27 & 48.32 & 78.19 & 94.92 & 99.51 & 99.99 & 100.00 & 100.00 & 100.00 \\
\hline \multicolumn{12}{|c|}{$10 \%$} \\
\hline$n=20$ & 10.00 & 11.31 & 12.44 & 14.01 & 17.14 & 21.09 & 25.60 & 32.84 & 41.72 & 50.93 & 61.79 \\
\hline$n=50$ & 10.00 & 12.38 & 17.38 & 27.48 & 42.57 & 59.78 & 76.74 & 90.27 & 96.61 & 99.15 & 99.89 \\
\hline$n=100$ & 10.00 & 16.83 & 36.61 & 66.88 & 90.83 & 98.68 & 99.90 & 100.00 & 100.00 & 100.00 & 100.00 \\
\hline \multicolumn{12}{|c|}{$\mathrm{D}, \mathrm{S}, \mathrm{NT}$} \\
\hline \multicolumn{12}{|c|}{$1 \%$} \\
\hline$n=20$ & 1.00 & 1.45 & 1.69 & 2.07 & 3.23 & 4.36 & 6.38 & 10.15 & 15.33 & 21.65 & 32.44 \\
\hline$n=50$ & 1.00 & 1.71 & 3.32 & 7.00 & 15.20 & 28.10 & 47.50 & 68.91 & 85.55 & 94.78 & 98.79 \\
\hline$n=100$ & 1.00 & 3.13 & 12.40 & 35.15 & 68.80 & 91.97 & 99.03 & 99.98 & 100.00 & 100.00 & 100.00 \\
\hline \multicolumn{12}{|c|}{$5 \%$} \\
\hline$n=20$ & 5.00 & 6.52 & 7.85 & 10.09 & 14.02 & 18.75 & 24.53 & 34.09 & 44.27 & 55.76 & 68.28 \\
\hline$n=50$ & 5.00 & 8.13 & 14.63 & 26.70 & 44.85 & 65.44 & 82.71 & 94.22 & 98.39 & 99.61 & 99.95 \\
\hline$n=100$ & 5.00 & 13.15 & 37.73 & 72.53 & 94.80 & 99.41 & 99.97 & 100.00 & 100.00 & 100.00 & 100.00 \\
\hline \multicolumn{12}{|c|}{$10 \%$} \\
\hline $\mathrm{n}=\mathbf{2 0}$ & 10.00 & 12.45 & 15.14 & 18.54 & 24.78 & 31.69 & 40.04 & 51.44 & 62.87 & 73.09 & 82.97 \\
\hline $\mathrm{n}=50$ & 10.00 & 15.39 & 25.85 & 42.71 & 63.87 & 82.32 & 93.21 & 98.36 & 99.60 & 99.93 & 99.99 \\
\hline$n=100$ & 10.01 & 24.78 & 58.10 & 88.19 & 98.89 & 99.91 & 100.00 & 100.00 & 100.00 & 100.00 & 100.00 \\
\hline \multicolumn{12}{|c|}{$\mathrm{D}, \mathrm{NS}, \mathrm{T}$} \\
\hline \multicolumn{12}{|c|}{$1 \%$} \\
\hline$n=20$ & 1.00 & 1.44 & 1.62 & 1.88 & 2.61 & 3.28 & 4.24 & 6.57 & 9.07 & 13.06 & 19.97 \\
\hline$n=50$ & 1.00 & 1.34 & 2.25 & 3.87 & 7.52 & 13.80 & 26.04 & 43.96 & 63.38 & 80.99 & 92.87 \\
\hline$n=100$ & 1.00 & 1.93 & 5.97 & 17.46 & 41.32 & 71.93 & 91.84 & 99.12 & 99.91 & 100.00 & 100.00 \\
\hline \multicolumn{12}{|c|}{$5 \%$} \\
\hline$n=20$ & 5.01 & 6.50 & 7.53 & 8.20 & 10.29 & 13.13 & 16.31 & 21.92 & 29.45 & 37.68 & 48.91 \\
\hline$n=50$ & 5.00 & 6.57 & 9.42 & 15.81 & 26.92 & 41.85 & 60.21 & 78.69 & 90.78 & 97.00 & 99.34 \\
\hline$n=100$ & 5.00 & 8.91 & 22.19 & 48.19 & 78.16 & 94.89 & 99.50 & 99.99 & 100.00 & 100.00 & 100.00 \\
\hline \multicolumn{12}{|c|}{$10 \%$} \\
\hline$n=20$ & 10.00 & 12.41 & 13.81 & 15.52 & 19.00 & 23.60 & 28.20 & 36.01 & 45.03 & 54.95 & 65.92 \\
\hline$n=50$ & 10.00 & 12.85 & 18.01 & 28.12 & 43.38 & 60.57 & 77.43 & 90.85 & 96.80 & 99.22 & 99.90 \\
\hline$n=100$ & 10.00 & 16.95 & 36.92 & 67.22 & 91.00 & 98.73 & 99.93 & 100.00 & 100.00 & 100.00 & 100.00 \\
\hline
\end{tabular}


Table 5

Power of the $t_{2}$ test. d.g.p.: $\left(1-B^{2}\right) x_{t}=\varepsilon_{t}$

\begin{tabular}{|c|c|c|c|c|c|c|c|c|c|c|c|}
\hline$\rho$ & 1.00 & 0.90 & 0.80 & 0.70 & 0.60 & 0.50 & 0.40 & \begin{tabular}{l|l|}
0.30 \\
\end{tabular} & 0.20 & 0.10 & 0.00 \\
\hline \multicolumn{12}{|l|}{$\mathrm{D}, \mathrm{S}, \mathrm{T}$} \\
\hline \multicolumn{12}{|c|}{$1 \%$} \\
\hline$n=20$ & 1.00 & 1.22 & 1.62 & 2.28 & 3.15 & 4.44 & 6.81 & 10.04 & 15.06 & 22.33 & 32.01 \\
\hline $\mathrm{n}=\mathbf{5 0}$ & 1.00 & 1.48 & 2.81 & $\begin{array}{l}6.67 \\
\end{array}$ & 13.39 & 25.50 & 44.65 & 66.16 & 83.26 & 93.75 & 98.45 \\
\hline$n=100$ & 1.00 & 3.06 & \begin{tabular}{l|l|}
10.89 \\
\end{tabular} & 32.64 & 65.30 & 90.60 & 98.60 & 99.95 & 100.00 & 100.00 & 100.00 \\
\hline \multicolumn{12}{|c|}{$5 \%$} \\
\hline$n=20$ & 5.00 & 5.89 & \begin{tabular}{|l|}
7.43 \\
\end{tabular} & \begin{tabular}{|l|}
9.48 \\
\end{tabular} & \begin{tabular}{|c|}
12.87 \\
\end{tabular} & 17.46 & 23.38 & 31.23 & \begin{tabular}{|c|}
41.57 \\
\end{tabular} & 52.30 & 64.86 \\
\hline$n=50$ & 5.00 & 7.85 & 13.94 & 25.95 & 43.72 & 64.57 & 82.26 & 93.80 & 98.32 & \begin{tabular}{|c|}
99.68 \\
\end{tabular} & 99.96 \\
\hline $\mathrm{n}=100$ & 5.00 & 14.04 & 38.52 & 70.91 & 93.85 & 99.45 & 99.97 & 100.00 & 100.00 & 100.00 & 100.00 \\
\hline \multicolumn{12}{|c|}{$10 \%$} \\
\hline$n=20$ & 10.00 & 11.50 & 14.57 & 18.13 & 23.20 & 30.16 & 38.55 & 48.95 & 60.08 & 70.59 & 80.85 \\
\hline$n=50$ & 10.00 & 15.08 & 25.43 & 42.34 & |63.43 & 81.61 & 93.11 & 98.33 & 99.65 & 99.96 & 100.00 \\
\hline$n=100$ & 10.00 & 24.91 & 58.06 & 87.90 & 98.70 & 99.94 & 100.00 & 100.00 & 100.00 & 100.00 & 100.00 \\
\hline \multicolumn{12}{|c|}{$\mathrm{D}, \mathrm{S}, \mathrm{NT}$} \\
\hline \multicolumn{12}{|c|}{$1 \%$} \\
\hline$n=20$ & 1.00 & 1.20 & 1.56 & 2.08 & 2.93 & 4.12 & \begin{tabular}{|l|}
6.13 \\
\end{tabular} & \begin{tabular}{|c|}
9.39 \\
\end{tabular} & 14.33 & 21.43 & 31.31 \\
\hline$n=50$ & 1.00 & 1.53 & 3.08 & 7.02 & 14.08 & 26.59 & 46.06 & 67.71 & 84.40 & 94.36 & 98.64 \\
\hline$n=100$ & 1.00 & 3.07 & 10.91 & 32.18 & 64.86 & 90.33 & 98.64 & 99.95 & 100.00 & 100.00 & 100.00 \\
\hline \multicolumn{12}{|c|}{$5 \%$} \\
\hline $\mathrm{n}=20$ & 5.00 & $\begin{array}{ll}6.13 \\
\end{array}$ & 7.54 & 9.83 & 13.34 & 18.00 & 23.94 & 32.32 & 43.15 & 54.39 & 66.91 \\
\hline$n=50$ & 5.01 & 7.91 & 13.94 & 26.05 & 43.74 & \begin{tabular}{|c|}
64.70 \\
\end{tabular} & 82.48 & 93.87 & 98.32 & 99.68 & 99.96 \\
\hline$n=100$ & 5.00 & 14.08 & 38.57 & 70.66 & 93.80 & 99.43 & 99.98 & 100.00 & 100.00 & 100.00 & 100.00 \\
\hline \multicolumn{12}{|c|}{$10 \%$} \\
\hline$n=20$ & 10.00 & 11.87 & 14.57 & 18.31 & 23.90 & 30.98 & 39.56 & 50.11 & 61.53 & \begin{tabular}{|l|}
71.88 \\
\end{tabular} & 82.17 \\
\hline$n=50$ & 9.99 & 15.15 & 25.45 & 42.58 & 63.89 & 81.94 & 93.35 & 98.42 & 99.67 & 99.97 & 100.00 \\
\hline$n=100$ & 10.00 & 25.01 & 58.28 & 87.59 & 98.65 & 99.91 & 100.00 & 100.00 & 100.00 & 100.00 & 100.00 \\
\hline \multicolumn{12}{|c|}{$\mathrm{D}, \mathrm{NS}, \mathrm{T}$} \\
\hline \multicolumn{12}{|c|}{$1 \%$} \\
\hline$n=20$ & 1.00 & 2.45 & 4.14 & 6.76 & 11.06 & \begin{tabular}{ll|}
17.20 \\
\end{tabular} & 25.07 & 36.50 & 48.87 & 62.21 & 74.77 \\
\hline $\mathrm{n}=\mathbf{5 0}$ & 1.00 & 4.77 & 12.31 & 27.43 & 51.28 & 74.27 & 90.17 & 97.39 & 99.46 & 99.92 & 100.00 \\
\hline$n=100$ & 1.00 & 11.21 & 42.15 & 80.00 & 97.39 & 99.87 & 100.00 & 100.00 & 100.00 & 100.00 & 100.00 \\
\hline \multicolumn{12}{|c|}{$5 \%$} \\
\hline $\mathrm{n}=\mathbf{2 0}$ & 5.00 & 13.57 & 20.93 & 30.92 & 43.56 & 56.70 & 69.29 & 80.78 & 89.25 & 94.13 & 97.39 \\
\hline $\mathrm{n}=\mathbf{5 0}$ & 5.00 & 20.52 & 44.15 & 70.51 & 89.79 & 97.65 & 99.56 & 99.95 & 100.00 & 100.00 & 100.00 \\
\hline$n=100$ & 5.00 & 40.84 & 85.60 & 98.85 & 99.96 & 100.00 & 100.00 & 100.00 & 100.00 & 100.00 & 100.00 \\
\hline \multicolumn{12}{|c|}{$10 \%$} \\
\hline$n=20$ & 10.00 & 25.45 & 37.51 & 50.40 & 65.41 & 78.03 & 86.74 & 93.30 & 96.60 & 98.50 & 99.37 \\
\hline $\mathrm{n}=\mathbf{5 0}$ & 10.00 & 37.39 & 67.40 & 89.11 & 97.87 & 99.67 & 99.95 & 100.00 & 100.00 & 100.00 & 100.00 \\
\hline $\mathrm{n}=100$ & 10.00 & 64.16 & 96.48 & 99.88 & 100.00 & 100.00 & 100.00 & \begin{tabular}{l|l}
100.00 \\
\end{tabular} & 100.00 & 100.00 & 100.00 \\
\hline
\end{tabular}


Table 6

Power of the $F_{12}$ test. d.g.p.: $\left(1-B^{2}\right) x_{t}=\varepsilon_{t}$

\begin{tabular}{|c|c|c|c|c|c|c|c|c|c|c|c|}
\hline$\rho$ & 1.00 & 0.90 & 0.80 & 0.70 & 0.60 & 0.50 & 0.40 & 0.30 & 0.20 & 0.10 & 0.00 \\
\hline \multicolumn{12}{|l|}{$\mathrm{D}, \mathrm{S}, \mathrm{T}$} \\
\hline \multicolumn{12}{|c|}{$1 \%$} \\
\hline$n=20$ & 1.00 & 1.02 & 1.21 & 1.70 & 2.44 & 3.61 & 5.40 & 8.16 & 12.72 & 19.63 & 28.75 \\
\hline$n=50$ & 1.00 & 1.63 & 3.94 & 8.77 & 19.48 & 38.81 & 62.66 & 82.36 & 94.00 & 98.67 & 99.73 \\
\hline$n=100$ & 1.00 & 3.39 & 16.29 & 50.37 & 85.82 & 98.49 & 99.94 & 100.00 & 100.00 & 100.00 & 100.00 \\
\hline \multicolumn{12}{|c|}{$\mathbf{5 \%}$} \\
\hline$n=20$ & 5.01 & 5.64 & 6.94 & 8.43 & 11.49 & 15.71 & 21.19 & 28.96 & 38.73 & 50.80 & 62.72 \\
\hline$n=50$ & 5.01 & 8.19 & 14.97 & 29.53 & 49.65 & 72.64 & 89.47 & 97.06 & 99.36 & 99.92 & 99.99 \\
\hline$n=100$ & 5.00 & 14.56 & 46.47 & 84.52 & 98.55 & 99.92 & 100.00 & 100.00 & 100.00 & 100.00 & 100.00 \\
\hline \multicolumn{12}{|c|}{$10 \%$} \\
\hline$n=20$ & 10.01 & 11.49 & 13.43 & 16.81 & 21.46 & 27.39 & 35.68 & 45.41 & 56.94 & 68.39 & 78.11 \\
\hline$n=50$ & 10.01 & 15.43 & 26.17 & 45.91 & 67.68 & 86.15 & 96.03 & 99.11 & 99.91 & 100.00 & 100.00 \\
\hline$n=100$ & 10.00 & 26.16 & 65.41 & 94.11 & 99.73 & 100.00 & 100.00 & 100.00 & 100.00 & 100.00 & 100.00 \\
\hline \multicolumn{12}{|c|}{$\mathrm{D}, \mathrm{S}, \mathrm{NT}$} \\
\hline \multicolumn{12}{|c|}{$1 \%$} \\
\hline $\mathrm{n}=\mathbf{2 0}$ & 1.01 & 1.18 & 1.69 & 2.48 & 3.83 & 5.92 & 9.38 & 14.36 & 22.05 & 33.15 & 45.66 \\
\hline $\mathbf{n}=\mathbf{5 0}$ & 1.01 & 2.19 & 5.49 & 13.84 & 30.43 & 54.96 & 78.79 & 92.67| & 98.16 & 99.72 & 99.97 \\
\hline$n=100$ & 1.00 & 4.76 & 25.44 & 67.57 & 94.70 & 99.70 & 100.00 & 100.00 & 100.00 & 100.00 & 100.00 \\
\hline \multicolumn{12}{|c|}{$5 \%$} \\
\hline$n=20$ & 5.00 & 6.13 & 7.85 & 10.81 & 15.15 & 21.43 & 29.93 & 40.56 & 53.30 & 66.27 & 77.14 \\
\hline $\mathrm{n}=\mathbf{5 0}$ & 5.00 & 9.64 & 20.79 & 41.22 & 65.62 & 86.09 & 96.32 & 99.26 & 99.92 & 100.00 & 100.00 \\
\hline$n=100$ & 5.01 & 19.44 & 61.33 & 93.79 & 99.78 & 100.00 & 100.00 & 100.00 & 100.00 & 100.00 & 100.00 \\
\hline \multicolumn{12}{|c|}{$10 \%$} \\
\hline $\mathbf{n}=\mathbf{2 0}$ & 10.00 & 12.16 & 15.45 & 20.72 & 27.39 & 36.39 & 47.89 & 59.82 & 72.00 & 81.90 & 89.15 \\
\hline$n=50$ & 10.00 & 18.35 & 35.10 & 59.53 & 81.81 & 94.72 & 99.02 & 99.81 & 99.98 & 100.00 & 100.00 \\
\hline$n=100$ & 10.01 & 33.09 & 78.42 & 98.36 & 99.96 & 100.00 & 100.00 & 100.00 & 100.00 & 100.00 & 100.00 \\
\hline \multicolumn{12}{|c|}{$\mathrm{D}, \mathrm{NS}, \mathrm{T}$} \\
\hline \multicolumn{12}{|c|}{$1 \%$} \\
\hline $\mathrm{n}=\mathbf{2 0}$ & 1.01 & 1.37 & 1.82 & 2.77 & 4.04 & 6.16 & 9.90 & 14.79 & 22.98 & 33.89 & 45.70 \\
\hline $\mathrm{n}=50$ & 1.00 & 2.27 & 5.71 & 13.97 & 30.22 & 54.30 & 78.31 & 92.33 & 98.02 & 99.71 & 99.94 \\
\hline$n=100$ & 1.00 & 5.33 & 26.62 & 68.92 & 94.98 & 99.72 & 100.00 & 100.00 & 100.00 & 100.00 & 100.00 \\
\hline \multicolumn{12}{|c|}{$5 \%$} \\
\hline $\mathrm{n}=\mathbf{2 0}$ & 5.01 & 6.63 & 8.88 & 12.03 & 16.54 & 23.05 & 31.73 & 42.99 & 55.22 & 68.18 & 78.25 \\
\hline $\mathrm{n}=50$ & 5.01 & 10.59 & 22.10 & 42.16 & 66.56 & 86.34 & 96.44 & 99.25 & 99.91 & 100.00 & 100.00 \\
\hline $\mathrm{n}=100$ & 5.01 & 20.11 & 61.40 & 93.68 & 99.70 & 100.00 & 100.00 & 100.00 & 100.00 & 100.00 & 100.00 \\
\hline \multicolumn{12}{|c|}{$10 \%$} \\
\hline $\mathrm{n}=\mathbf{2 0}$ & 10.00 & 13.12 & 16.67 & 22.01 & 28.39 & 38.30 & 48.80 & 60.92 & 72.59 & 82.47 & 89.20 \\
\hline $\mathrm{n}=50$ & 10.01 & 19.14 & 35.90 & 59.88 & 81.56 & 94.57 & 98.91 & 99.81 & 99.99 & 100.00 & 100.00 \\
\hline$n=100$ & 10.00 & 34.16 & 78.64 & 98.25 & 99.95 & 100.00 & 100.00 & 100.00 & 100.00 & 100.00 & 100.00 \\
\hline
\end{tabular}


Table 7

Power of the $t_{1}$ test. d.g.p.: $(1-B) x_{t}=\varepsilon_{t}$

\begin{tabular}{|c|c|c|c|c|c|c|c|c|c|c|c|}
\hline$\rho$ & 1.00 & 0.90 & $\mathbf{0 . 8 0}$ & 0.70 & 0.60 & 0.50 & 0.40 & $\mathbf{0 . 3 0}$ & 0.20 & 0.10 & 0.00 \\
\hline \multicolumn{12}{|l|}{$\mathrm{D}, \mathrm{S}, \mathrm{T}$} \\
\hline \multicolumn{12}{|c|}{$1 \%$} \\
\hline$n=20$ & 1.00 & 1.13 & 1.38 & 2.03 & 2.58 & 3.82 & 5.19 & 6.49 & 8.65 & 11.15 & 13.99 \\
\hline$n=50$ & 1.00 & 1.91 & 4.05 & 10.49 & 20.56 & 34.37 & 49.95 & 65.13 & 75.84 & 85.13 & 91.46 \\
\hline$n=100$ & 1.00 & 4.69 & 23.67 & 58.87 & 86.32 & 97.21 & 99.51 & 99.94 & 100.00 & 100.00 & 100.00 \\
\hline \multicolumn{12}{|c|}{$\mathbf{5 \%}$} \\
\hline$n=20$ & 5.00 & 5.60 & 6.83 & 9.01 & 11.56 & 15.53 & 19.58 & 24.24 & 28.59 & 34.57 & 39.58 \\
\hline$n=50$ & 5.00 & 8.22 & 16.78 & 33.01 & 51.80 & 69.10 & 82.38 & 90.67 & 94.97 & 97.96 & 99.01 \\
\hline$n=100$ & 5.00 & 18.46 & 56.69 & 88.89 & 98.34 & 99.81 & 99.99 & 100.00 & 100.00 & 100.00 & 100.00 \\
\hline \multicolumn{12}{|c|}{$10 \%$} \\
\hline$n=20$ & 10.00 & 11.10 & 13.44 & 17.14 & 21.75 & 27.02 & 33.49 & 38.91 & 44.95 & 52.21 & 57.85 \\
\hline$n=50$ & 10.00 & 15.48 & 29.41 & 50.08 & 69.36 & 83.11 & 92.20 & 96.58 & 98.35 & 99.47 & 99.78 \\
\hline$n=100$ & 10.01 & 31.40 & 75.05 & 96.06 & 99.65 & 99.97 & 100.00 & 100.00 & 100.00 & 100.00 & 100.00 \\
\hline \multicolumn{12}{|c|}{$\mathrm{D}, \mathrm{S}, \mathrm{NT}$} \\
\hline \multicolumn{12}{|c|}{$1 \%$} \\
\hline $\mathrm{n}=\mathbf{2 0}$ & 1.00 & 1.58 & 2.03 & 3.51 & 5.19 & 7.92 & 10.86 & 14.88 & 18.34 & 23.80 & 28.44 \\
\hline $\mathbf{n}=\mathbf{5 0}$ & 1.00 & 3.16 & 8.77 & 22.26 & 41.03 & 60.13 & 76.25 & 86.96 & 93.07 & 97.08 & 98.63 \\
\hline$n=100$ & 1.00 & 8.69 & 42.70 & 81.94 & 96.97 & 99.64 & 99.96 & 100.00 & 100.00 & 100.00 & 100.00 \\
\hline \multicolumn{12}{|c|}{$5 \%$} \\
\hline$n=20$ & 5.00 & 7.39 & 10.32 & 15.72 & 21.38 & 28.45 & 35.98 & 44.13 & 50.76 & 58.72 & 65.34 \\
\hline $\mathrm{n}=\mathbf{5 0}$ & 5.00 & 12.92 & 30.76 & 55.31 & 76.85 & 89.11 & 95.74 & 98.53 & 99.35 & 99.80 & 99.95 \\
\hline$n=100$ & 5.00 & 31.44 & 81.52 & 98.14 & 99.91 & $\begin{array}{l}99.99 \\
\end{array}$ & 100.00 & 100.00 & 100.00 & 100.00 & 100.00 \\
\hline \multicolumn{12}{|c|}{$10 \%$} \\
\hline $\mathbf{n}=\mathbf{2 0}$ & 10.00 & 14.12 & 19.21 & 27.02 & 35.45 & 44.44 & 53.27 & 61.87 & 68.62 & 75.14 & 80.36 \\
\hline$n=50$ & 10.00 & 23.15 & 48.71 & 73.44 & 89.41 & 96.17 & 98.83 & 99.67 & 99.85 & 99.98 & 100.00 \\
\hline$n=100$ & 10.00 & 49.72 & 92.97 & 99.65 & 99.97 & 100.00 & 100.00 & 100.00 & 100.00 & 100.00 & 100.00 \\
\hline \multicolumn{12}{|c|}{$\mathrm{D}, \mathrm{NS}, \mathrm{T}$} \\
\hline \multicolumn{12}{|c|}{$1 \%$} \\
\hline $\mathrm{n}=\mathbf{2 0}$ & 1.00 & 1.11 & 1.37 & 2.08 & 2.62 & 3.71 & 5.00 & 6.73 & 8.88 & 11.49 & 14.22 \\
\hline $\mathrm{n}=50$ & 1.00 & 1.82 & 3.98 & 10.36 & 20.40 & 34.16 & 49.88 & 64.93 & 75.91 & 85.14 & 91.43 \\
\hline$n=100$ & 1.00 & 4.53 & 23.14 & 58.13 & 85.80 & 97.05 & 99.48 & 99.93 & 100.00 & 100.00 & 100.00 \\
\hline \multicolumn{12}{|c|}{$5 \%$} \\
\hline $\mathrm{n}=\mathbf{2 0}$ & 5.00 & 5.67 & 6.88 & 8.98 & 11.72 & 15.64 & 19.60 & 24.31 & 29.05 & 34.75 & 39.66 \\
\hline $\mathrm{n}=50$ & 5.00 & 8.18 & 16.78 & 32.80 & 51.80 & 68.99 & 82.35 & 90.70 & 94.97 & 97.93 & 99.03 \\
\hline $\mathrm{n}=100$ & 5.00 & 18.69 & 57.03 & 89.08 & 98.43 & 99.80 & 99.99 & 100.00 & 100.00 & 100.00 & 100.00 \\
\hline \multicolumn{12}{|c|}{$10 \%$} \\
\hline $\mathrm{n}=\mathbf{2 0}$ & 10.00 & 11.15 & 13.32 & 16.91 & 21.67 & 26.73 & 33.05 & 39.03 & 45.08 & 52.21 & 58.04 \\
\hline $\mathrm{n}=50$ & 10.00 & 15.46 & 29.16 & 49.85 & 69.23 & 83.01 & 92.34 & 96.61 & 98.35 & 99.44 & 99.79 \\
\hline$n=100$ & 9.99 & 31.37 & 74.83 & 96.07 & 99.63 & 99.97 & 100.00 & 100.00 & 100.00 & 100.00 & 100.00 \\
\hline
\end{tabular}


Table 8

Power of the $t_{2}$ test. d.g.p.: $(1+B) x_{t}=\varepsilon_{t}$

\begin{tabular}{|c|c|c|c|c|c|c|c|c|c|c|c|}
\hline$\rho$ & 1.00 & 0.90 & 0.80 & 0.70 & $\begin{array}{l}0.60 \\
\end{array}$ & 0.50 & 0.40 & $\begin{array}{l}0.30 \\
\end{array}$ & 0.20 & 0.10 & 0.00 \\
\hline \multicolumn{12}{|l|}{$\mathrm{D}, \mathrm{S}, \mathrm{T}$} \\
\hline \multicolumn{12}{|c|}{$1 \%$} \\
\hline $\mathrm{n}=\mathbf{2 0}$ & 1.00 & 1.39 & 2.25 & 3.60 & 5.17 & 7.83 & 11.18 & 14.44 & 18.40 & 23.65 & 28.53 \\
\hline $\mathrm{n}=\mathbf{5 0}$ & 1.00 & 2.56 & 8.09 & 20.29 & 38.09 & 56.83 & 73.85 & 85.13 & 91.66 & 96.24 & 98.12 \\
\hline$n=100$ & 1.00 & 9.20 & 43.94 & 82.53 & 97.13 & 99.65 & 99.96 & 100.00 & 100.00 & 100.00 & 100.00 \\
\hline \multicolumn{12}{|c|}{$5 \%$} \\
\hline$n=20$ & 5.00 & 7.25 & 10.43 & 15.15 & 20.46 & 27.74 & 35.75 & 42.92 & 49.79 & 57.83 & 63.68 \\
\hline $\mathrm{n}=50$ & 5.00 & 12.79 & 31.65 & 55.87 & 77.19 & 89.49 & 96.01 & 98.46 & 99.44 & 99.90 & 99.97 \\
\hline$n=100$ & 4.99 & 31.76 & 80.57 & 98.04 & 99.88 & 99.99 & 100.00 & 100.00 & 100.00 & 100.00 & 100.00 \\
\hline \multicolumn{12}{|c|}{$10 \%$} \\
\hline$n=20$ & 10.00 & 13.78 & 19.59 & 26.87 & 34.56 & 44.31 & 53.33 & 61.31 & 68.04 & 75.08 & 79.90 \\
\hline$n=50$ & 10.00 & 23.48 & 48.87 & 74.27 & 89.88 & 96.25 & 98.94 & 99.56 & 99.90 & 99.99 & 99.99 \\
\hline$n=100$ & 10.00 & 50.86 & 92.92 & 99.71 & 100.00 & 100.00 & 100.00 & 100.00 & 100.00 & 100.00 & 100.00 \\
\hline \multicolumn{12}{|c|}{$\mathrm{D}, \mathrm{S}, \mathrm{NT}$} \\
\hline \\
\hline $\mathrm{n}=\mathbf{2 0}$ & 1.00 & 1.49 & 2.24 & 3.55 & 5.29 & 7.77 & 11.15 & 14.57 & 18.71 & 24.07 & 29.04 \\
\hline$n=50$ & 1.00 & 2.54 & 8.08 & 20.08 & 37.72 & 56.65 & 73.77 & \begin{tabular}{l|l|}
85.09 \\
\end{tabular} & 91.65 & 96.34 & 98.14 \\
\hline$n=100$ & 1.00 & 8.94 & 43.40 & 82.03 & 97.07 & 99.63 & 99.96 & 100.00 & 100.00 & 100.00 & 100.00 \\
\hline \multicolumn{12}{|c|}{$5 \%$} \\
\hline$n=20$ & 4.99 & 6.91 & 9.70 & 14.46 & 19.69 & 26.45 & 34.44 & 41.39 & 48.43 & 56.47 & 62.64 \\
\hline $\mathrm{n}=\mathbf{5 0}$ & 5.00 & 12.59 & 31.30 & 55.61 & 76.85 & 89.34 & 95.97 & 98.45 & 99.44 & 99.88 & 99.97 \\
\hline$n=100$ & 4.99 & 31.51 & 80.40 & 98.03 & 99.88 & 99.99 & 100.00 & 100.00 & 100.00 & 100.00 & 100.00 \\
\hline \multicolumn{12}{|c|}{$10 \%$} \\
\hline $\mathrm{n}=\mathbf{2 0}$ & 10.00 & 13.60 & 19.13 & 26.41 & 34.19 & 43.78 & 52.74 & 60.94 & 67.69 & 74.99 & 79.71 \\
\hline$n=50$ & 10.00 & 23.42 & 48.55 & 73.96 & 89.77 & 96.17 & 98.94 & 99.54 & 99.90 & 99.99 & 99.99 \\
\hline$n=100$ & 10.00 & 50.48 & 92.79 & 99.68 & 100.00 & 100.00 & 100.00 & 100.00 & 100.00 & 100.00 & 100.00 \\
\hline \multicolumn{12}{|c|}{$\mathrm{D}, \mathrm{NS}, \mathrm{T}$} \\
\hline \multicolumn{12}{|c|}{$1 \%$} \\
\hline$n=20$ & 1.00 & 3.88 & 8.28 & 14.50 & 22.22 & 31.02 & 41.14 & 50.60 & 59.17 & 67.26 & 73.66 \\
\hline $\mathrm{n}=50$ & 1.00 & 10.96 & 35.38 & 64.81 & 85.81 & 94.66 & 98.47 & 99.48 & 99.83 & 99.99 & 99.99 \\
\hline$n=100$ & 1.00 & 34.25 & 88.16 & 99.40 & 99.99 & 100.00 & 100.00 & 100.00 & 100.00 & 100.00 & 100.00 \\
\hline \multicolumn{12}{|c|}{$5 \%$} \\
\hline$n=20$ & 5.00 & 18.69 & 33.27 & |48.71 & 62.80 & 73.75 & 82.46 & 88.24 & 91.70 & 95.19 & 96.64 \\
\hline $\mathrm{n}=\mathbf{5 0}$ & 5.00 & 38.34 & 76.65 & 94.59 & 98.88 & 99.77 & 99.95 & 99.99 & 100.00 & 100.00 & 100.00 \\
\hline$n=100$ & 5.00 & 78.08 & 99.43 & 99.98 & 100.00 & 100.00 & 100.00 & 100.00 & 100.00 & 100.00 & 100.00 \\
\hline \multicolumn{12}{|c|}{$10 \%$} \\
\hline $\mathrm{n}=\mathbf{2 0}$ & 10.00 & 34.42 & 54.40 & 70.50 & 82.34 & 89.37 & 93.99 & 96.44 & 97.75 & 98.83 & 99.28 \\
\hline $\mathrm{n}=\mathbf{5 0}$ & 10.00 & 61.55 & 92.01 & 98.79 & 99.80 & 99.96 & 100.00 & 100.00 & 100.00 & 100.00 & 100.00 \\
\hline$n=100$ & 10.00 & 93.04 & 99.94 & 100.00 & 100.00 & 100.00 & 100.00 & 100.00 & 100.00 & 100.00 & 100.00 \\
\hline
\end{tabular}


Table 9

Results of ADF tests

\begin{tabular}{|c|c|c|c|c|c|c|c|c|c|}
\hline & & $\begin{array}{l}\text { Series } \\
\text { (i) }\end{array}$ & & $\begin{array}{l}\text { Series } \\
\text { (ii) }\end{array}$ & & $\begin{array}{c}\text { Series } \\
\text { (iii) }\end{array}$ & & $\begin{array}{c}\text { Series } \\
\text { (iv) }\end{array}$ & \\
\hline $\begin{array}{l}\text { Fitted } \\
\text { Model }\end{array}$ & Test & Statistic & Outcome & Statistic & Outcome & Statistic & Outcome & Statistic & Outcome \\
\hline $\mathbf{n}(\mathbf{q})$ & & $66(1)$ & & $32(3)$ & & $22(3)$ & & $22(1)$ & \\
\hline \multirow[t]{2}{*}{$\mathrm{D}, \mathrm{S}, \mathrm{T}$} & $t_{d t}$ & -0.473 & & -0.439 & & -0.930 & & 1.712 & $\mathbf{I}(\mathbf{1})$ \\
\hline & $\mathrm{F}_{\mathrm{ut}}$ & 1.824 & & 2.281 & & 2.009 & & 10.194 & \\
\hline \multirow[t]{2}{*}{ D, S, NT } & $t_{d}$ & -1.946 & & -1.900 & $\mathbf{I}(\mathbf{1})$ & 0.989 & & n.a. & \\
\hline & $\mathrm{F}_{\mathrm{ud}}$ & 3.226 & & 4.571 & & 1.971 & & n.a. & \\
\hline ND, NS, NT & $\mathrm{t}$ & 1.837 & I(1) & n.a. & & 1.848 & $\mathbf{I}(\mathbf{1})$ & n.a. & \\
\hline
\end{tabular}

Notes: " $n$ " is the sample size; "q" is the "augmentation level" for the tests; "D, S, T" denotes "drift, seasonal dummy, trend"; "D, S, NT" denotes "drift, seasonal dummy, no trend"; "ND, NS, NT" denotes "no drift, no seasonal dummy, no trend". The other notation is defined in the text. 
Table 10

Results of seasonal unit root tests

\begin{tabular}{|c|c|c|c|c|c|c|c|c|c|}
\hline & & $\begin{array}{l}\text { Series } \\
\text { (i) }\end{array}$ & & $\begin{array}{l}\text { Series } \\
\text { (ii) }\end{array}$ & & $\begin{array}{l}\text { Series } \\
\text { (iii) }\end{array}$ & & $\begin{array}{c}\text { Series } \\
\text { (iv) }\end{array}$ & \\
\hline $\begin{array}{l}\text { Fitted } \\
\text { Model }\end{array}$ & Test & Statistic & Outcome & Statistic & Outcome & Statistic & Outcome & Statistic & Outcome \\
\hline \multirow[t]{4}{*}{$\begin{array}{c}\mathrm{D}, \mathrm{S}, \mathrm{T} \\
(\mathrm{q})\end{array}$} & & (2) & & (2) & & (1) & & (1) & \\
\hline & $\mathrm{t}_{1}$ & -0.439 & Zero root & -0.473 & Zero root & -1.075 & Zero root & -0.382 & Zero root \\
\hline & $\mathrm{t}_{2}$ & -2.369 & $\pi$ root & -5.072 & & -2.303 & $\pi$ root & 0.054 & $\pi$ root \\
\hline & $\mathrm{F}_{12}$ & 2.887 & SI(1) & 13.113 & & 4.561 & SI(1) & 0.120 & SI(1) \\
\hline \multirow[t]{4}{*}{$\begin{array}{c}\text { D, S, NT } \\
\text { (q) }\end{array}$} & & (2) & & (2) & & (1) & & (1) & \\
\hline & $\mathrm{t}_{1}$ & -1.900 & Zero root & -1.946 & Zero root & 0.219 & Zero root & 0.963 & Zero root \\
\hline & $\mathrm{t}_{2}$ & -2.419 & $\pi$ root & -5.376 & & -2.569 & $\pi$ root & -0.355 & $\pi$ root \\
\hline & $\mathrm{F}_{12}$ & 4.896 & SI(1) & 20.866 & & 3.405 & SI(1) & 0.626 & SI(1) \\
\hline \multirow[t]{4}{*}{$\begin{array}{c}\text { D, NS, T } \\
\text { (q) }\end{array}$} & & (2) & & (0) & & (1) & & (1) & \\
\hline & $\mathrm{t}_{1}$ & -0.405 & Zero root & -0.464 & Zero root & -1.661 & Zero root & -0.516 & Zero root \\
\hline & $\mathrm{t}_{2}$ & -1.103 & $\pi$ root & -5.152 & & -1.253 & $\pi$ root & 0.494 & $\pi$ root \\
\hline & $\mathrm{F}_{12}$ & 0.685 & SI(1) & 13.530 & & 2.434 & SI(1) & 0.149 & SI(1) \\
\hline \multirow[t]{4}{*}{$\begin{array}{c}\mathrm{D}, \mathrm{NS}, \mathrm{NT} \\
(\mathrm{q})\end{array}$} & & (2) & & $(0)$ & & (2) & & (1) & \\
\hline & $\mathrm{t}_{1}$ & -1.896 & Zero root & -2.003 & Zero root & 1.420 & Zero root & 0.837 & Zero root \\
\hline & $t_{2}$ & -1.145 & $\pi$ root & -5.458 & & -0.510 & $\pi$ root & 0.055 & $\pi$ root \\
\hline & $\mathrm{F}_{12}$ & 2.518 & SI(1) & 21.551 & & 1.332 & SI(1) & 0.967 & SI(1) \\
\hline \multirow[t]{4}{*}{$\begin{array}{l}\text { ND, NS, NT } \\
\text { (q) }\end{array}$} & & (2) & & (0) & & (2) & & (1) & \\
\hline & $\overline{t_{1}}$ & 0.434 & Zero root & 1.837 & Zero root & 1.752 & Zero root & 1.276 & Zero root \\
\hline & $\mathrm{t}_{2}$ & -1.181 & $\pi$ root & -6.440 & & -0.748 & $\pi$ root & -0.130 & $\pi$ root \\
\hline & $\mathrm{F}_{12}$ & 0.799 & SI(1) & 38.202 & & 1.935 & SI(1) & 1.718 & SI(1) \\
\hline
\end{tabular}


Figure 1

Power of the $\mathrm{t}_{1}$ test. Drift, seasonal dummy and trend in regression. $10 \%$ size. (d.g.p.: $\left.\left(1-\mathrm{B}^{2}\right) \mathrm{x}_{\mathrm{t}}=\varepsilon_{\mathrm{t}}\right)$

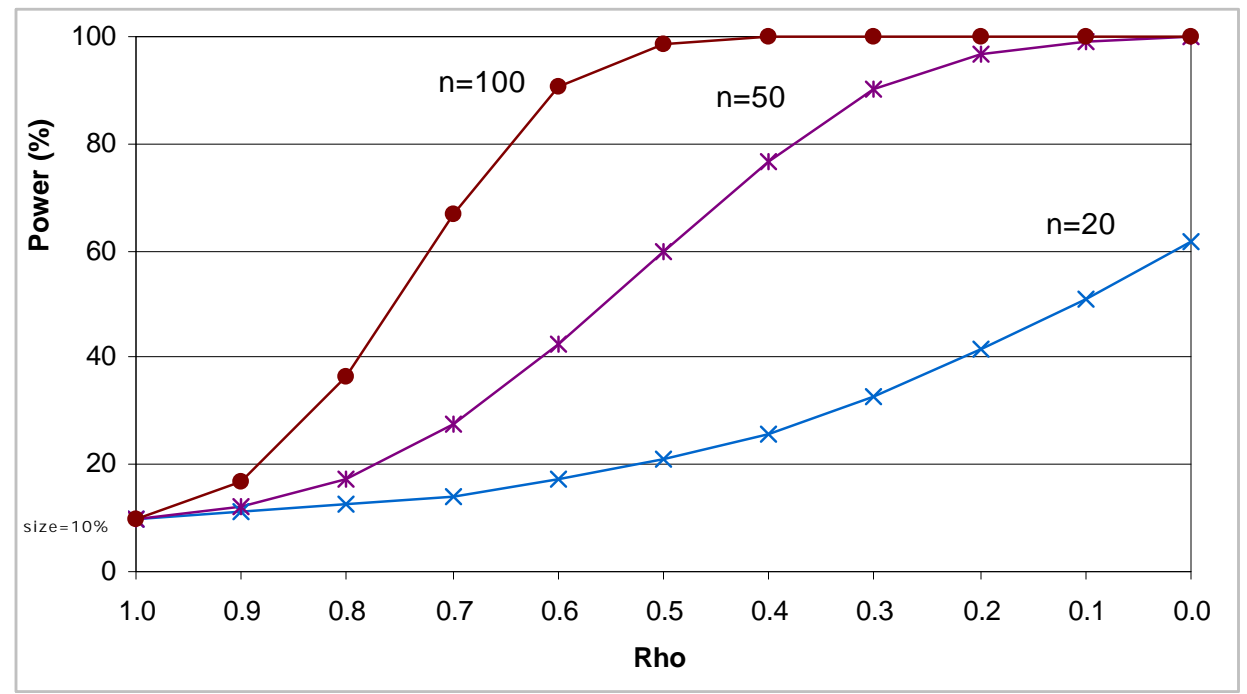

Figure 2

Power of the $t_{2}$ test. Drift, seasonal dummy and trend in regression. $10 \%$ size. (d.g.p.: $\left.\left(1-\mathrm{B}^{2}\right) \mathrm{x}_{\mathrm{t}}=\varepsilon_{\mathrm{t}}\right)$

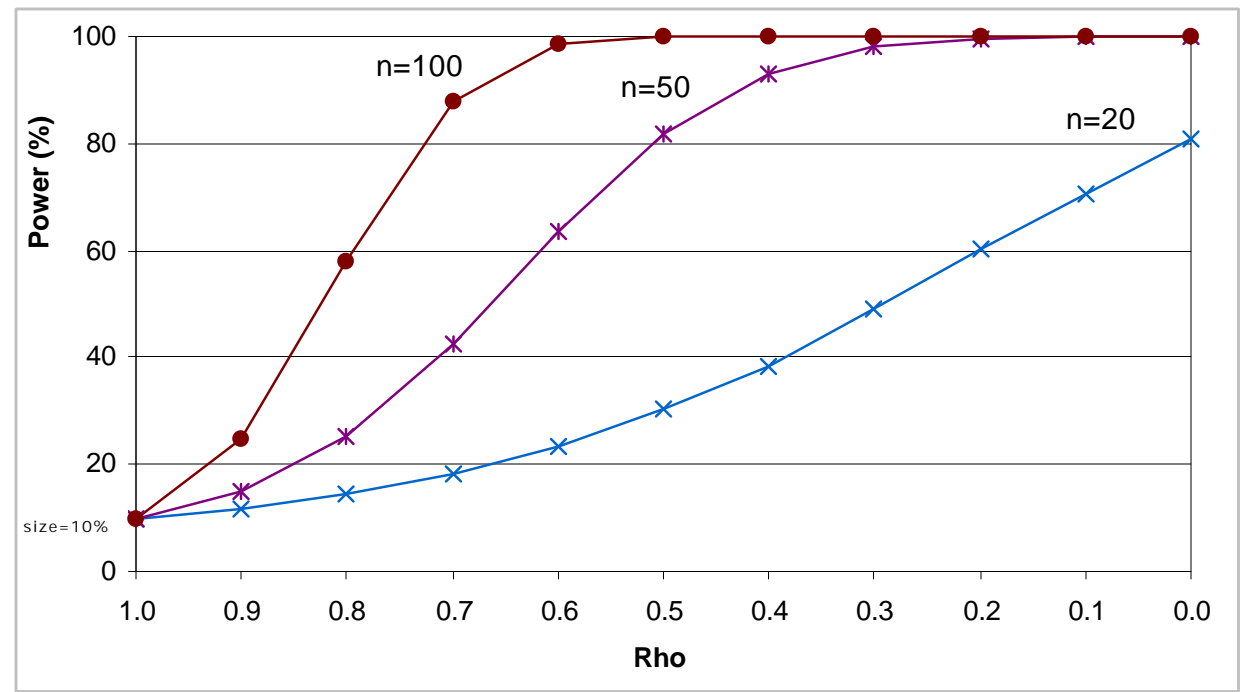


Figure 3

Power of the $\mathrm{F}_{12}$ test. Drift, seasonal dummy and trend in regression. $10 \%$ size.

(d.g.p.: $\left.\left(1-\mathrm{B}^{2}\right) \mathrm{x}_{\mathrm{t}}=\varepsilon_{\mathrm{t}}\right)$

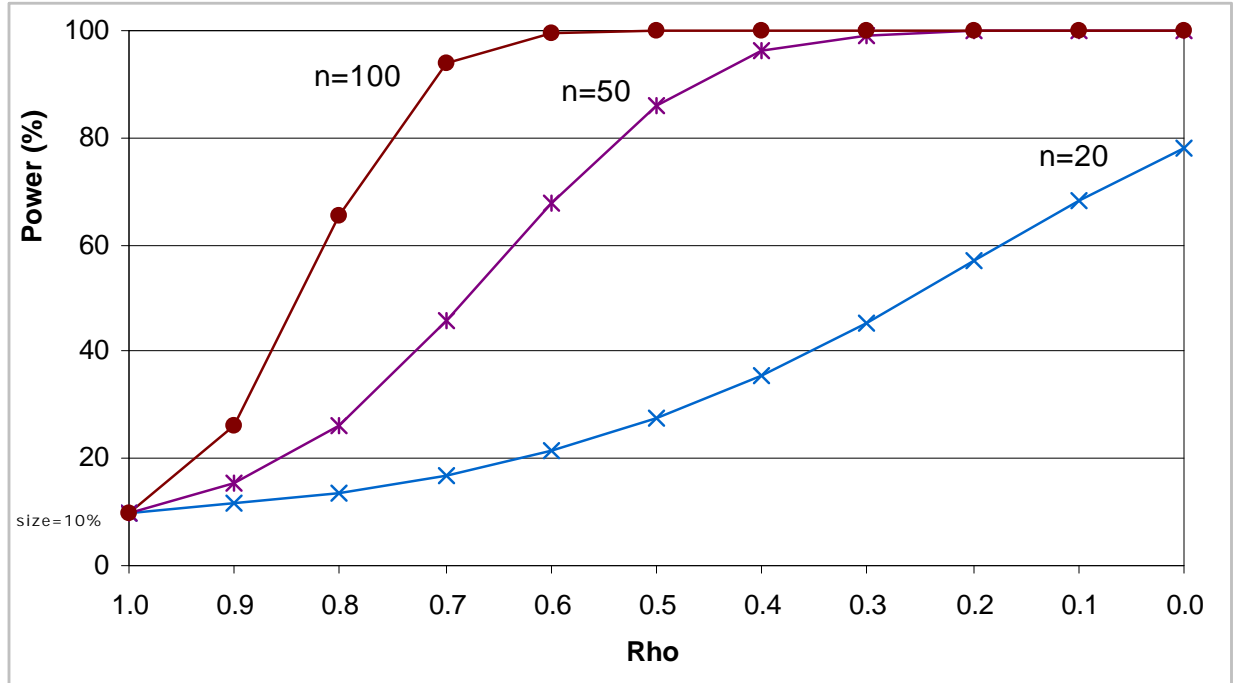

Figure 4

Power of the $t_{1}$ test. Drift, seasonal dummy and trend in regression. $10 \%$ size.

(d.g.p.: $\left.(1-B) \mathrm{X}_{t}=\varepsilon_{t}\right)$

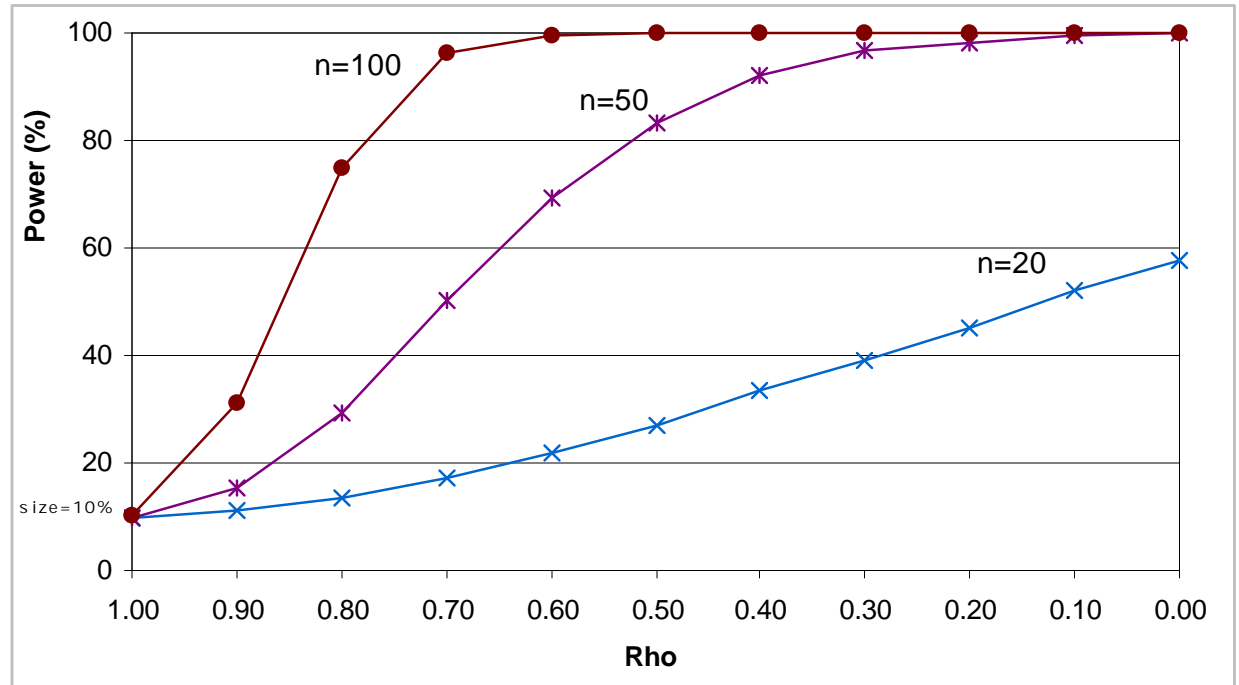


Figure 5

Power of the $t_{2}$ test. Drift, seasonal dummy and trend in regression. $10 \%$ size. (d.g.p.: $\left.(1+B) x_{t}=\varepsilon_{t}\right)$

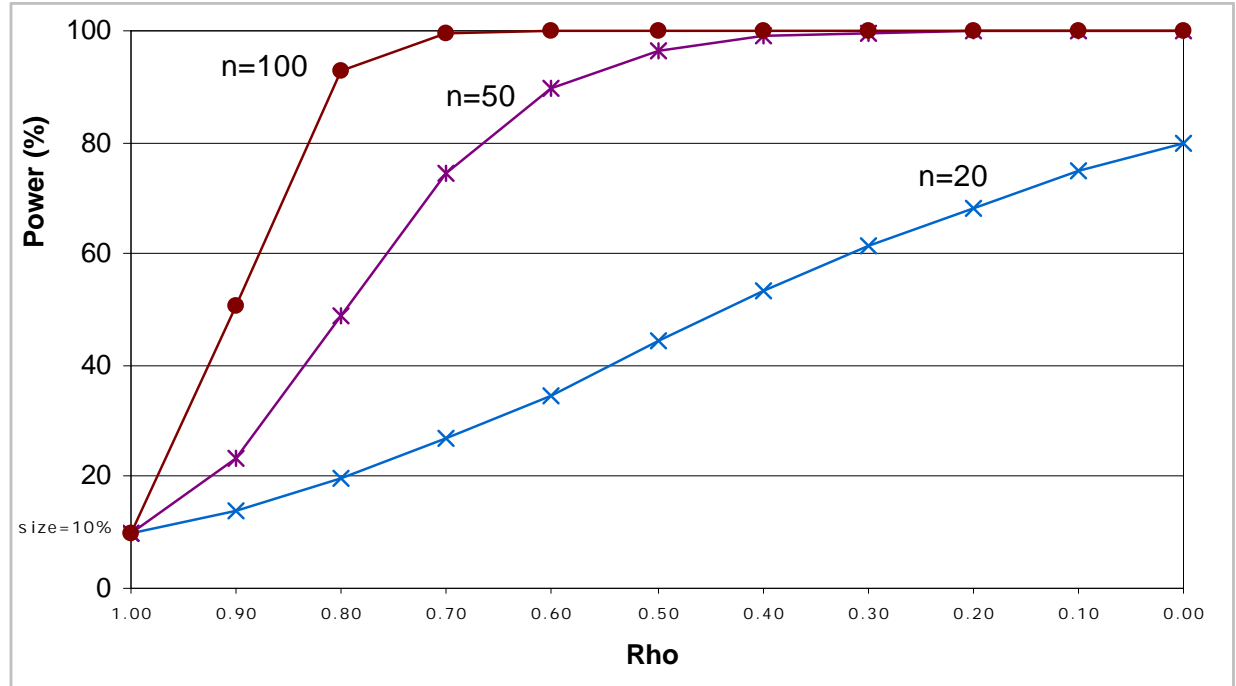



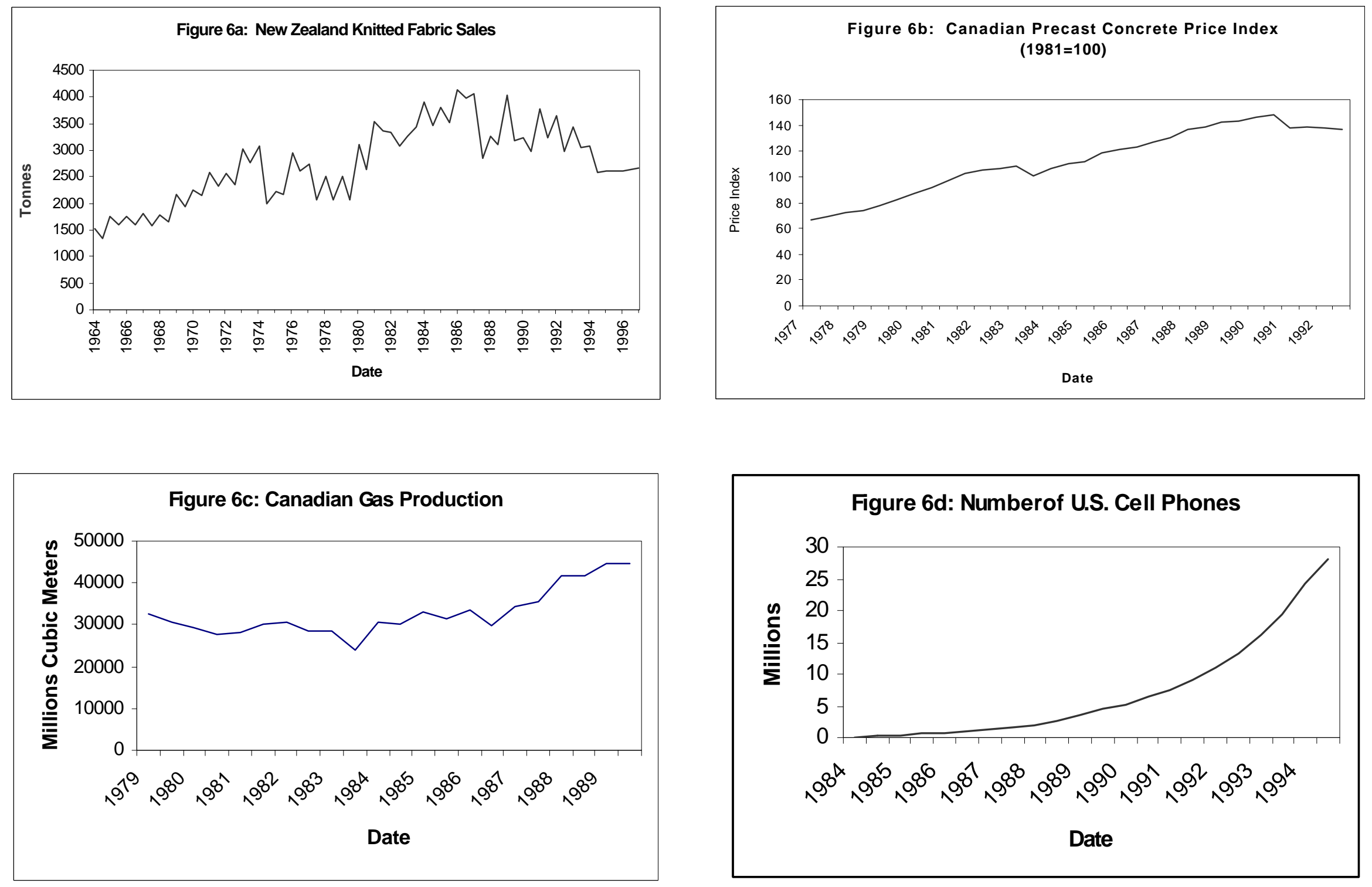


\section{References}

Beaulieu, J. J., Miron, J. A., 1993. Seasonal unit roots in aggregate U.S. data. Journal of Econometrics 55, 305-328.

Chan, N.H., Wei, C. Z., 1988. Limiting distributions of least squares estimates of unstable autoregressive processes. Annals of Statistics, 16, 367-401.

Dickey, D. A., Fuller, W. A., 1979. Distribution of the estimators for autoregressive time series with a unit root. Journal of the American Statistical Association, 74, 427-431.

Dickey, D. A., Fuller, W. A., 1981. Likelihood ratio statistics for autoregressive time series with a unit root. Econometrica, 49, 1057-1072.

Dickey, D. A., Hasza, D. P., Fuller, W. A., 1984. Testing for unit roots in seasonal time series. Journal of the American Statistical Association 79, 355-367.

Dods, J.L., Giles, D.E.A., 1995. Alternative strategies for 'augmenting' the Dickey-Fuller test: sizerobustness in the face of pre-testing. Journal of Statistical Computation and Simulation, 53, 243-258.

Dolado, J.J., Jenkinson, T., Sosvilla-Rivero, S., 1990, Cointegration and unit roots. Journal of Economic Surveys, 4, 249-273.

Franses, P. H., 1991. Seasonality, nonstationarity and the forecasting of monthly time series. International Journal of Forecasting 7, 199-208.

Franses, P. H., 1998. Time Series Models for Business and Economic Forecasting. Cambridge University Press, Cambridge.

Franses, P. H., Hobijn, B., 1997. Critical values for unit root tests in seasonal time series. Journal of Applied Statistics 24, 25-47.

Fuller, W. A., 1976. Introduction to Statistical Time Series. Wiley, New York.

Ghysels, E., Lee, H. S., Noh, J., 1994. Testing for unit roots in seasonal time series: some theoretical extensions and a Monte Carlo investigation. Journal of Econometrics 62, 415442.

Hylleberg, S., 1992. Modelling Seasonality. Oxford University Press, Oxford.

Hylleberg, S., Engle, R. F., Granger, C. W. J., Yoo, B. S., 1990. Seasonal integration and cointegration. Journal of Econometrics 44, 215-238.

Kunst, R. M.,1997. Testing for cyclical non-stationarity in autoregressive processes. Journal of Time Series Analysis 18, 325-330. 
MacKinnon, J.G., 1991. Critical values for cointegration tests, in R.F. Engle and C.W.J. Granger, eds., Long-Run Economic Relationships. Oxford University Press, Oxford, 267276.

Osborn, D. R., Rodrigues, P. M. M., 1998. The asymptotic distributions of seasonal unit root tests: a unifying approach. Discussion Paper 9811, School of Economic Studies, University of Manchester.

Osborn, D. R., Chui, A. P. L., Smith, J. P., Birchenhall, C. R., 1988. Seasonality and the order of integration of consumption. Oxford Bulletin of Economics and Statistics 50, 361-377.

Petroleum Monitoring Agency Canada, various years. Canadian Petroleum Industry Monitoring Reports.

Phillips, P. C. B., 1987. Time series regression with a unit root . Econometrica 55, 277-302.

Said, S. E., Dickey, D. A.,1984. Testing for unit roots in autoregressive-moving average models of unknown order. Biometrika 71, 599-607.

SHAZAM, 1997. SHAZAM Econometrics Computer Program, User's Reference Manual, Version 8.0. McGraw-Hill, New York.

Smith, R. J., Taylor, A. M. R., 1998. Additional critical values and asymptotic representations for seasonal unit root tests. Journal of Econometrics, 85, 269-288.

Statistics Canada , 1998. Cansim Main Index.

Statistics New Zealand, 1998. INFOS Databank.

Stock, J. H., 1988. A class of tests for integration and cointegration. Mimeo., Kennedy School of Government, Harvard University, Cambridge, MA.

Waterman, R., 1998. <www-stat.wharton.upenn.edu/ waterman/fsw/datasets/txt/Cellular.txt>. 


\section{Footnotes}

1. See also Franses and Hobijn (1997). Smith and Taylor (1998) provide a recent elegant discussion of the HEGY tests for quarterly data.

2. The assumption of a martingale difference sequence is stronger than that of serially uncorrelated errors, but weaker than independence (Hamilton, 1994, p.190).

3. See also Phillips (1987) and Stock (1988).

4. In Table 9, $\mathrm{t}_{\mathrm{dt}}$ denotes the ADF unit root "t-test" with drift and trend terms included in the fitted regression; $F_{u t}$ is the corresponding ADF "F-test" for a unit root and zero trend; $t_{d}$ is the unit root "t-test" with a drift but no trend in the fitted regression; $F_{u d}$ is the corresponding "F-test" for a unit root and a zero drift; and $t$ is the ADF unit root test when the fitted regression has no drift or trend term included. Finite-sample critical values for our "t-tests" and "F-tests" come from MacKinnon (1991), and from Dickey and Fuller (1979, 1981), respectively.

5. The simulation results of Dods and Giles (1995) favour this approach, in terms of low pre-test size distortion, for sample sizes such as ours. In fact the results are not sensitive to the method used to choose this augmentation level.

6. The need to include this dummy variable follows from the results of Ghysels et al. (1994). There was no evidence that any of the series other than (iv) may be I(2).

7. In the case of series (iv) the plotted series is for the number of cell phones, rather than the six-monthly increase in this number. The latter series is the one that is analyzed. 